\title{
Life after Adolescent and Adult Moderate and Severe Traumatic Brain Injury: Self-Reported Executive, Emotional, and Behavioural Function 2-5 Years after Injury
}

\author{
Torun Gangaune Finnanger, ${ }^{1,2,3}$ Alexander Olsen, ${ }^{4,5}$ Toril Skandsen,, \\ Stian Lydersen, ${ }^{1}$ Anne Vik, ${ }^{6,7}$ Kari Anne I. Evensen, ${ }^{8,9}$ Cathy Catroppa, ${ }^{10,11}$ \\ Asta K. Håberg, ${ }^{4}$ Stein Andersson, ${ }^{12,13}$ and Marit S. Indredavik ${ }^{1,2}$ \\ ${ }^{1}$ Regional Centre for Child and Youth Mental Health and Child Welfare-Central Norway, Faculty of Medicine, \\ Norwegian University of Science and Technology (NTNU), 7491 Trondheim, Norway \\ ${ }^{2}$ Division of Mental Healthcare, Department of Child and Adolescent Psychiatry, St. Olavs Hospital, Trondheim University Hospital, \\ 7006 Trondheim, Norway \\ ${ }^{3}$ Children's Clinic, St. Olavs Hospital, Trondheim University Hospital, 7006 Trondheim, Norway \\ ${ }^{4}$ MI Lab and Department of Circulation and Medical Imaging, Norwegian University of Science and Technology, \\ 7491 Trondheim, Norway \\ ${ }^{5}$ Department of Physical Medicine and Rehabilitation, St. Olavs Hospital Trondheim University Hospital, 7006 Trondheim, Norway \\ ${ }^{6}$ Department of Neuroscience, Faculty of Medicine, Norwegian University of Science and Technology, 7491 Trondheim, Norway \\ ${ }^{7}$ Neuroclinic, Department of Neurosurgery, St. Olavs Hospital, Trondheim University Hospital, 7006 Trondheim, Norway \\ ${ }^{8}$ Department of Public Health and General Practice, Department of Laboratory Medicine, Children and Women's Health, \\ Norwegian University of Science and Technology, 7491 Trondheim, Norway \\ ${ }^{9}$ Department of Physiotherapy, Trondheim Municipality, Norway \\ ${ }^{10}$ Child Neuropsychology, Murdoch Children's Research Institute, Melbourne, VIC 3052, Australia \\ ${ }^{11}$ Department of Pediatrics and School of Psychological Sciences, University of Melbourne, Melbourne, VIC 3010, Australia \\ ${ }^{12}$ Department of Psychosomatic Medicine, Oslo University Hospital, 0424 Oslo, Norway \\ ${ }^{13}$ Department of Psychology, University of Oslo, 0373 Oslo, Norway
}

Correspondence should be addressed to Torun Gangaune Finnanger; torun.g.finnanger@ntnu.no

Received 25 June 2015; Accepted 1 September 2015

Academic Editor: John H. Zhang

Copyright (C) 2015 Torun Gangaune Finnanger et al. This is an open access article distributed under the Creative Commons Attribution License, which permits unrestricted use, distribution, and reproduction in any medium, provided the original work is properly cited.

\footnotetext{
Survivors of moderate-severe Traumatic Brain Injury (TBI) are at risk for long-term cognitive, emotional, and behavioural problems. This prospective cohort study investigated self-reported executive, emotional, and behavioural problems in the late chronic phase of moderate and severe TBI, if demographic characteristics (i.e., age, years of education), injury characteristics (Glasgow Coma Scale score, MRI findings such as traumatic axonal injury (TAI), or duration of posttraumatic amnesia), symptoms of depression, or neuropsychological variables in the first year after injury predicted long-term self-reported function. Self-reported executive, emotional, and behavioural functioning were assessed among individuals with moderate and severe TBI $(N=67$, age range 15-65 years at time of injury) 2-5 years after TBI, compared to a healthy matched control group $(N=72)$. Results revealed significantly more attentional, emotional regulation, and psychological difficulties in the TBI group than controls. Demographic and early clinical variables were associated with poorer cognitive and emotional outcome. Fewer years of education and depressive symptoms predicted greater executive dysfunction. Younger age at injury predicted more aggressive and rule-breaking behaviour. TAI and depressive symptoms predicted Internalizing problems and greater executive dysfunction. In conclusion, age, education, TAI, and depression appear to elevate risk for poor long-term outcome, emphasising the need for long-term follow-up of patients presenting with risk factors.
} 


\section{Introduction}

Adolescents and adults surviving moderate and severe Traumatic Brain Injury (TBI) often experience long-lasting cognitive, emotional, and behavioural problems [1-4]. In particular executive dysfunction has been demonstrated to have a profound impact on the ability to resume education, employment, and independent living [5-7]. Further, TBI is associated with an increased risk of developing symptoms of psychiatric disorders such as depression [8], anxiety [9], substance abuse [10], personality problems [3, 11], and behavioural changes such as aggression $[12,13]$. All of those symptoms affect reintegration into the community [14], and therefore it is of great importance to identify those at risk for poorer long-term outcomes.

Executive function is a complex, overarching concept that refers to all functions related to goal-directed regulation of thoughts, actions, and emotions, including problemsolving, monitoring ongoing operations, switching between operations, emotion regulation, initiation of behaviour, and inhibition of nonadaptive behaviour $[15,16]$. While some components of executive functions such as monitoring and switching cognitive operations may be assessed by standardized neuropsychological tests, other aspects such as regulating emotions and actions which are often more detrimental to adaptive functioning are often not captured by such tests $[16$, 17] and are better measured by questionnaires [18]. Further, the relationship between self-reported and performancebased executive function after TBI is far from established $[19,20]$.

Several self-report inventories have been developed aiming to assess not only the goal-directed regulation of thoughts, but also regulation of actions and emotions. Studies have demonstrated significant changes in self-reported executive function after TBI related to the individuals overall ability to regulate thoughts, emotions, and behaviour [21, 22]. However, there is a further need for studies utilizing more finetuned assessment tools providing more detailed profiles of typical executive problems after TBI. Although descriptions of typical profiles of self-reported executive problems have been examined as long as 10 years after childhood TBI [23, 24], there are no previous studies that have investigated such long-term consequences of TBI sustained in adolescence and adulthood.

Previous research has shown that a broad assessment is necessary to capture the variety of emotional and behavioural problems that persons may experience after TBI, including both Internalizing emotional problems such as depression or anxiety as well as Externalizing problems such as aggressive behaviour $[1,9,13,25]$. In fact, compared with the general population, a substantially larger proportion of individuals with TBI qualify for an Axis I diagnosis according to DSMIV, with depression, anxiety, and substance abuse most commonly observed $[9,18]$. However, people with TBI may also experience a greater degree of subclinical symptoms compared to healthy individuals, which are better captured by questionnaires $[18,26]$. Furthermore, while studies have described self-reported symptoms of depression [27], anxiety [28], and aggression [12] after TBI previously, there is a paucity of studies investigating Internalizing and externalizing simultaneously following TBI sustained in adolescence and adulthood.

Assessing cognitive, emotional, and behavioural changes after TBI using self-report gives access to unobservable, internal experiences to which only the person with TBI is privileged. A number of adult TBI studies have shown reasonable correspondence between self-report and family report $[4,29,30]$. However, it has been suggested that persons with severe injuries may underreport their problems which is hypothesised to be caused by reduced self-awareness or insight [31]. Nevertheless, the appropriateness of using proxy reports from family has been debated in the broad psychology literature, in particular for children and adolescents [32, 33], suggesting the possibility that family report reflects their own distress rather than that of the person with TBI $[34,35]$. Further, it has been shown that the persons' own perception of their problems may influence how well they manage to reintegrate into the community $[6,36,37]$. Taken together, these findings warrant a focus on descriptions of typical selfreported problems as it could inform clinicians as to which symptoms should be targeted during rehabilitation and to inform general clinical decision making.

When considering possible predictors of self-reported executive problems after TBI sustained in late adolescence and adulthood, association has been found with length of education [38], lesion localization [29], Glasgow Coma Scale (GCS) score [39, 40], and concurrent emotional status (i.e., depression) [39]. However, to our knowledge reports of an association between long-term self-reported executive problems after a TBI sustained in adolescence and adulthood and duration of PTA and traumatic diffuse axonal injury (TAI) are lacking. Executive functions rely upon network interactions between several cortical, subcortical, and cerebellar brain regions $[16,41,42]$, leaving them vulnerable to traumatic axonal injury (TAI) as a consequence of TBI [4345]. Detecting TAI in vivo has been challenging, and it has further been demonstrated that valuable information about the magnitude of TAI may be lost if MRI is not performed in an early phase after injury [46]. While no relationship has been found between white matter integrity and concurrent self-reported executive function in the chronic phase after moderate and severe TBI utilizing diffusion tensor imaging (DTI) [47], better self-reported executive function in the chronic phase after moderate-to-severe TBI has been associated with compensatory brain activations as measured with functional magnetic resonance imaging (fMRI) [48]. However, no previous studies have investigated associations between self-reported executive function in the chronic phase and TAI as detected by clinical MRI in the early phase.

Associations with self-reported emotional and behavioural change after TBI are equally complex. Development of depression and anxiety after TBI has been observed to be associated with low socioeconomic resources (i.e., fewer years of education) $[9,25]$, while aggression and antisocial personality problems have been found to be associated with age $[9,26]$. Evidence of associations between injury severity and 
later neuropsychiatric problems has been conflicting $[9,18$, $49,50]$, with some studies reporting no association at all [51]. Furthermore, the occurrence of mood disorders has been related to dysfunction in neural circuits involving cortical and subcortical structures [52], but only a few of those studies have included magnetic resonance imaging (MRI) findings $[53,54]$ and reviews in the field are inconclusive $[9,18]$.

This study adresses the gaps in the previous litterature by investigating long-term cognitive, emotional, and behavioural self-reported outcomes after moderate and severe TBI sustained in adolecense and adulthood by utilizing finetuned tools assessing a broad range of possible symtoms; providing methodologicaly sound methods such as prospective recruitment, comparisons to a large, matched control group; and providing high quality imaging methods for assessing the impact of TAI. The aims of this study were to (1) investigate long-term self-reported executive, emotional, and behavioural function after moderate-to-severe TBI sustained in late adolescence and adulthood and (2) to explore the association between demographic, injury-related, psychological, global outcome, and neuropsychological factors, as obtained in the postacute phase and later self-reported problems. We hypothesised that persons with TBI would report more overall problems with executive function as well as more symptoms of emotional and behavioural problems than healthy individuals 2-5 years after the injury. Based on previous literature using fine-tuned tools such as the Behaviour Rating Inventory of Executive Function-Adult version (BRIEF-A) $[30,38]$, we expected that problems with problem-solving [30] and working memory [38] would be among the most frequently reported executive cognitive problems. Moreover, we hypothesised that symptoms of depression, anxiety, and aggression would be frequently reported 2-5 years after injury. As the literature shows conflicting evidence of the impact of injury-related measures [39, 40, 47, 51, 53, 54], we specifically investigated the predictive value of injury severity measures such as GCS score, length of PTA, and TAI as detected by MRI in the early phase after TBI. While concurrent emotional status has been demonstrated to affect self-report $[29,55]$, we wished to extend previous findings by examining whether emotional status during the first year after injury could affect self-report as long as $2-5$ years after injury. Based on previous findings [39, 40, 53], we hypothesised that measures of injury severity would be negatively associated with long-term self-reported executive, emotional, and behavioural function. Finally, we explored whether age at injury, length of education, performance-based cognitive function, global function as well as emotional status could explain some of the variance in outcome variables.

\section{Methods}

2.1. Study Design and Participants. From October 2004 to July 2008, 236 consecutive patients with moderate and severe TBI according to the Head Injury Severity Scale (HISS) criteria [56] were admitted to the Department of Neurosurgery at St. Olavs Hospital, Trondheim University Hospital, Norway, and registered in a database. Five did not consent to any follow-up. Participants registered in this database were contacted between February 2009 and August 2010 if they were more than one year after injury and fulfilled the inclusion criteria: (1) 15-65 years of age at the time of injury; (2) fluency in Norwegian; and (3) Glasgow Outcome Score Extended (GOSE) $\geq 5$ at time of assessment (follow-up). Exclusion criteria were ongoing or preinjury substance abuse, neurological or psychiatric conditions, or previous moderateto-severe TBI.

Of the 231 patients in the database, 51 died, and 40 were outside the age range. Forty-five were excluded because of premorbid or ongoing illness endorsed in the unstructured clinical interview during the hospital stay after the injury $(n=28)$, being not fluent in the Norwegian language $(n=$ $4)$, and GOSE scores $<5(n=13)$. This left 95 patients eligible for this study, of which $74(78 \%)$ consented to a single follow-up assessment between 2 and 5 years after injury. Seven were excluded from analysis owing to invalid questionnaire completion. This left $67 \mathrm{TBI}$ survivors for the full analysis. There were no differences in the distribution of age, gender, education, or injury severity between participants and nonparticipants. Description of patient selection and nonparticipants as well as timeline is described in the flowchart in Figure 1.

Forty-nine patients (injured October 2004-October 2007) consented to participate in a study on longitudinal cognitive outcome with neuropsychological assessment and screening for depressive symptoms 3 and 12 months after injury, as well as participating in the follow-up study 25 years after injury. Eighteen participants (injured October 2004-October 2008) consented to participate in the 2-5 years after injury follow-up study, but not to participate in the assessments at 3 and 12 months after injury. There were no differences in the distribution of age, gender, education, or injury severity between the persons participating in the neuropsychological assessment + follow-up compared to those participating only in the follow-up, except that a larger proportion of participants in the first group had PTA durations of $>1$ week (Pearson's Chi-square, $p=0.042$ ). There were no differences between the participants as a whole group compared to the nonparticipants.

Sex-, age-, and education-matched healthy control participants were recruited from the family and friends of the patients with TBI, hospital employees, and through advertisement. Six of 78 recruited controls were excluded because of previously diagnosed psychiatric or neurological conditions (discovered on the day of testing, $n=3$ ) or invalid completion of the forms $(n=3)$. As a result, 72 control participants were included.

2.2. Material and Procedures. Figure 2 describes the timeline for the various measures.

2.2.1. Long-Term Outcome Measures (2-5 Years after Injury). Participants completed questionnaires that assessed selfreported executive, emotional, and behavioural problems at follow-up (mean $2.9 \pm 0.9$ years after injury, range: $2-5$ years after injury). A few participants were unable to complete all questionnaires. While $17(25 \%)$ of the participants were between 15 and 18 years of age at the time of injury 


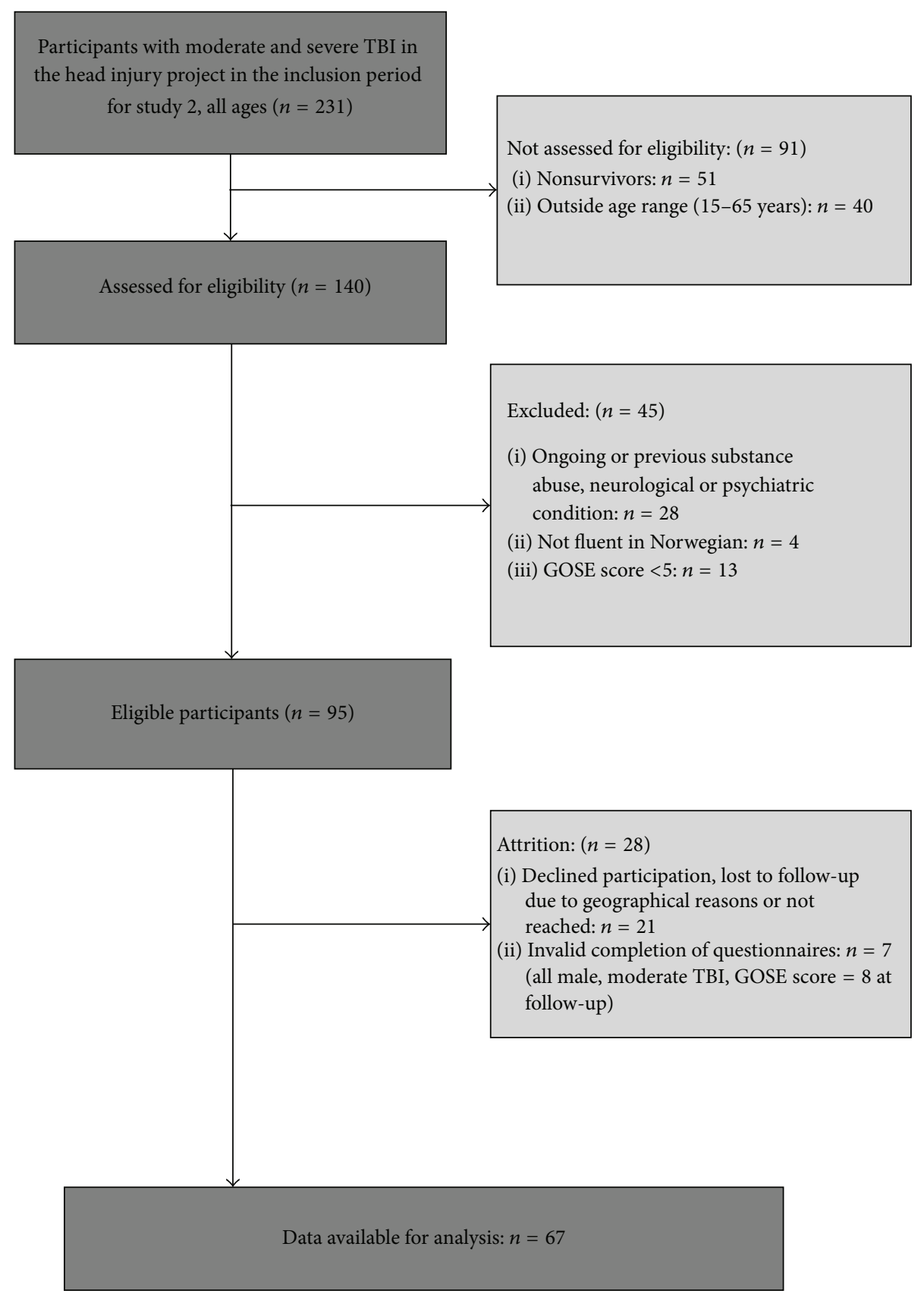

FIGURE 1: Flowchart illustrating sample selection and description of nonparticipants.

(adolescents), all but one participant were $\geq 18$ years of age when completing the questionnaires at follow-up 2-5 years after injury and one was 17 years old. We used a self-report form and an interview to estimate the number of years of education completed at the time of follow-up.

2.2.2. Self-Reported Executive Function. Self-reported executive function was assessed with the BRIEF-A questionnaire, which consists of 75 items that measure behavioural, emotional, and cognitive aspects of executive function. It features sound psychometric properties $[57,58]$, good reliability, and large-scale norms $[17,58]$. Each item is rated on a three-point frequency scale ( $0=$ never; $1=$ sometimes; $2=$ often $)$. Five items are designed to detect invalid response styles (inconsistencies or negativity). Seventy items generate three composite index scores and nine subscale scores. The subscales Inhibit, Shift, Emotional Control, and Self-Monitor generate the Behaviour Regulation Index (BRI), while the subscales Initiate, Working Memory, Plan/Organize, Task Monitor, and Organization of Materials constitute the Metacognitive Index (MI). In addition, a Global Executive Composite (GEC) is calculated from all 70 items. The BRIEF-A reference manual classifies the clinical range as $T$-score $\geq 65$, with higher scores indicative of poorer function. The technical manual classifies 


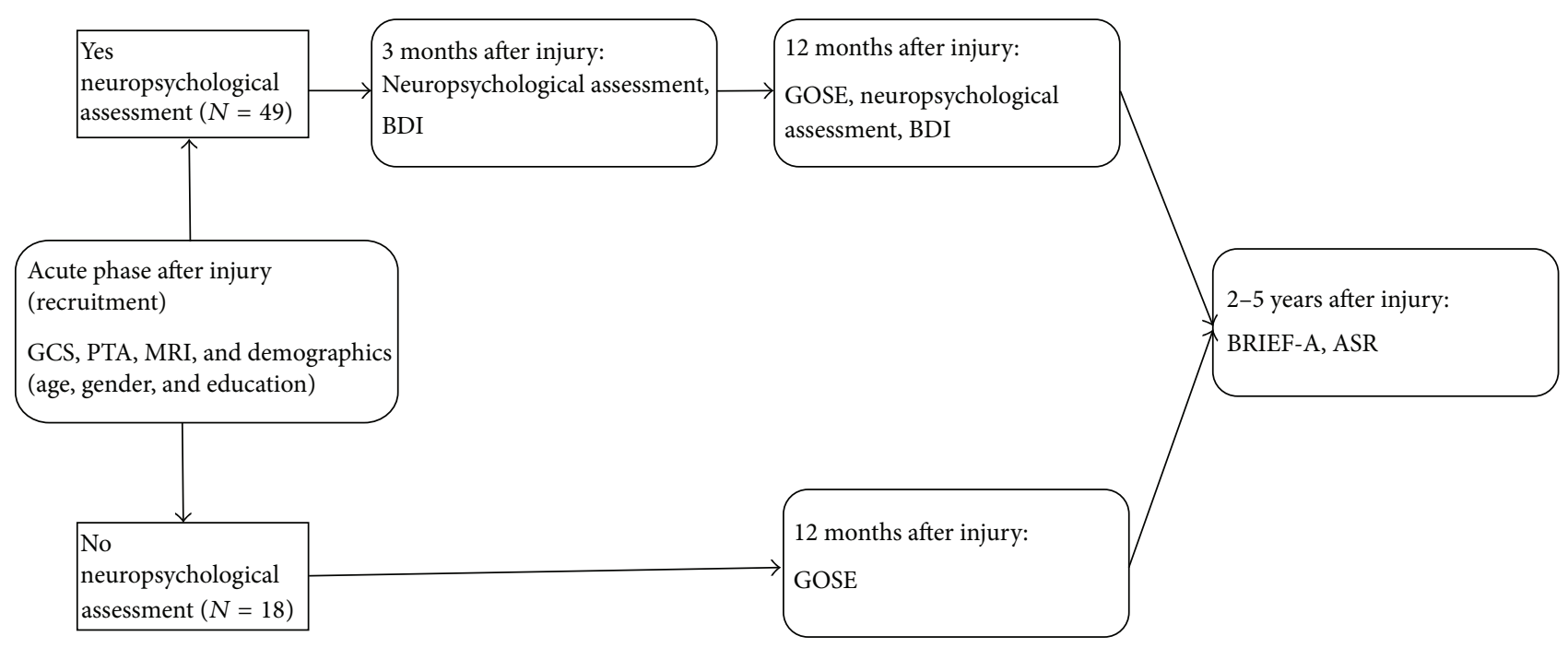

FIGURE 2: Timeline displaying the time points during data collection and the assessments for this study.

a score on the negativity scale of $>4$ and a score on the inconsistency scale as $>7$ as an invalid report. Any reports that were classified as invalid according to these criteria were excluded from further analysis.

\subsubsection{Self-Reported Emotional and Behavioural Problems.} Self-reported emotional and behavioural problems were assessed with the ASEBA: Adult Self-Report (ASR) Form [59]. The ASR consists of one section that measures adaptive functioning (38 items) and one section that measures emotional and behavioural problems (126 items) on a threepoint scale $(0=$ statement not true; $1=$ statement sometimes true; 2 = statement very true). Eight syndrome scales are generated: anxious/depressed, withdrawn, somatic complaints, thought problems, attention problems, aggressive behaviour, rule-breaking behaviour, and intrusive behaviour. The form yields three composite scores: Total problems, Internalizing problems (sum of the scales anxious/depressed, withdrawn, and somatic complaints), and Externalizing problems (sum of the scales aggressive, rule-breaking, and intrusive behaviour). The form also yields six DSM-IV-oriented scales: depressive, anxiety, somatic, avoidant personality, attention deficit hyperactivity disorder (ADHD), and antisocial personality problems. Items considered critical to diagnostic categories in the DSM-IV constitute the critical items scale. The ASEBA reference manual [59] recommends using raw scores when presenting descriptive data and borderline range using $T$ scores as the threshold in research (clinical cut-off) with higher scores indicative of poorer function. The clinical range is classified as $T$-score $\geq 70$ and the borderline range is classified as $T$-score $\geq 65$ for the syndrome scales; the respective ranges are classified as $T$-score $\geq 63$ and $\geq 60$ for the composite scales [59]. The subscales inattention and hyperactivity/impulsive are set at $\geq 97$ th percentile and $\geq 93 \mathrm{rd}$ percentile, respectively.

\subsection{Measures of Predictors of Long-Term Outcome (at Injury and 12 Months after Injury)}

2.3.1. Injury-Related Variables: GCS Score, PTA, and Presence of TAI on Early MRI. GCS score was recorded at or after admittance if the patient deteriorated or before intubation in cases of prehospital intubation. GCS scores of 9-13 were classified as moderate TBI and scores $\leq 8$ were considered severe TBI $[56,60]$. Duration of PTA was categorized as $\leq 1$ week or $>1$ week. The presence of TAI was assessed from the earliest MRI (1.5 Tesla) examination performed at median 10 days after injury (range $=1-120$ days). The scan protocol included T1- and T2-weighted sequences, a T2*-weighted gradient echo sequence, fluid-attenuated inversion recovery (FLAIR) sequences, and diffusion-weighted imaging. MRI parameters and the evaluation procedure have been reported in previous studies $[61,62]$.

2.3.2. Global Function 12 Months after Injury. Global TBI related outcome was assessed with the Glasgow Outcome Scale Extended (GOSE) [63] structured interview at 12 months after injury for all participants recruited from the initial data base $(n=66)$.

\subsubsection{Subgroup Analyses: Neuropsychological and Emotional} Assessment. The subgroup was assessed at 3 months after injury, with performance-based neuropsychological tests grouped into cognitive domains covering processing speed $[64,65]$, attention [66], memory [67-69], and executive function $[65,70]$. Table 1 displays the cognitive domains and neuropsychological tests used. Raw scores were converted to $T$-scores applying normative data provided by the test manufacturers, except for the Symbol Digit Modality test in which a normative sample quoted by Lezak et al. [71] was used. Standardized scores on the individual neuropsychological tests were grouped into composite scores for each 
TABLE 1: Overview of performance-based neuropsychological tests assessing cognitive function in the subsample grouped into cognitive domains 3 months after TBI.

\begin{tabular}{|c|c|c|c|}
\hline Neuropsychological tests & & & Reference \\
\hline \multicolumn{4}{|l|}{ Motor function } \\
\hline Grooved Pegboard & Dominant hand & & {$[63]$} \\
\hline \multicolumn{4}{|l|}{ Information processing speed } \\
\hline Delis Kaplan Executive Function System & & (D-KEFS) & \\
\hline Trail Making Test & $\begin{array}{l}\text { Condition } 2 \text { (number sequencing) } \\
\text { Condition } 3 \text { (letter sequencing) }\end{array}$ & (TMT) & \multirow[t]{2}{*}[65]{} \\
\hline Color-Word Interference Test & $\begin{array}{l}\text { Condition } 1 \text { (color naming) } \\
\text { Condition } 2 \text { (word reading) }\end{array}$ & (CWIT) & \\
\hline Symbol Digit Modality Test & $\begin{array}{l}\text { Oral version } \\
\text { Written version }\end{array}$ & $(\mathrm{SDMT})$ & {$[64]$} \\
\hline \multicolumn{4}{|l|}{ Attention } \\
\hline Conners' Continuous Performance Test II & & (CPT-II) & {$[66]$} \\
\hline \multicolumn{4}{|l|}{ Visual memory } \\
\hline Continuous Visual Memory Test & & (CVMT) & {$[69]$} \\
\hline Rey-Osterrieth Complex Figure Test & & $(\mathrm{ROCF})$ & {$[68]$} \\
\hline \multicolumn{4}{|l|}{ Verbal memory } \\
\hline California Verbal Learning Test-II & & (CVLT-II) & {$[67]$} \\
\hline \multicolumn{4}{|l|}{ Executive function } \\
\hline $\begin{array}{l}\text { Wisconsin Card Sorting Test computer } \\
\text { version }\end{array}$ & & (WCST) & {$[70]$} \\
\hline Verbal Fluency Test (D-KEFS) & $\begin{array}{l}\text { Condition } 1 \text { (letter fluency), } \\
\text { Condition } 3 \text { (category change) }\end{array}$ & & \\
\hline TMT (D-KEFS) & Condition 4 (number-letter sequencing) & & {$[65]$} \\
\hline CWIT (D-KEFS) & $\begin{array}{l}\text { Condition } 3 \text { (inhibition) } \\
\text { Condition } 4 \text { (inhibition/switching) }\end{array}$ & & \\
\hline Tower Test (D-KEFS) & & & \\
\hline
\end{tabular}

cognitive domain. $T$-scores were used in the analysis. These tests have demonstrated adequate validity and reliability [71]. The Vocabulary and Matrix Reasoning subtests of the Wechsler Abbreviated Scale of Intelligence (WASI) were used to estimate IQ [72]. Depressive symptoms were assessed with the Beck Depression Inventory (BDI) at both 3 months $(n=$ $47)$ and 12 months $(n=44)$ after injury [73].

2.4. Ethics. The Regional Committee for Medical Research Ethics approved the study protocol. Written consent was obtained from patients aged $\geq 16$ years at injury and from both participants and their parents if patients were aged $<16$ years at injury.

2.5. Statistical Methods. Demographic characteristics, injury severity characteristics, and the different cognitive domains are presented as mean ( \pm standard deviation, SD) for normally distributed data, and otherwise as median with interquartile range (IQR; 25th to 75th percentile). For missing data, we used available case analysis, utilizing all cases for which the variables were present. We reported $95 \%$ confidence intervals (CIs) where relevant, and two-sided $p$ values $<0.05$ were considered statistically significant. $p$ values between 0.01 and 0.05 should be interpreted with caution owing to multiple hypotheses. Statistical analyses were performed with SPSS 18.0.

To describe differences in function between persons with TBI and controls, independent samples $t$-tests based on 2000 bootstrap samples were used. The Kruskal-Wallis test and Mann-Whitney $U$ test were used for nonnormally distributed data. Effect sizes were calculated as Cohen's $d$ based on pooled variance $\left(d_{\text {pooled }}\right)$ [74]. Cohen defined $d$ of 0.8 as large, 0.5 as medium, and 0.2 as small effect sizes [75]. Differences in proportions were compared using the Chi-squared test, the unconditional $z$-pooled test [76], and the Newcombe confidence interval $[77,78]$.

To test associations between outcome measures and predictors, linear regression analyses were performed with composite scores from BRIEF-A and ASR as dependent variables; preinjury variables, injury-related variables, and GOSE scores were employed as covariates. In the subgroup analyses, neuropsychological test scores at 3 months after injury and BDI were employed as covariates. These covariates were included separately and then adjusted for age at injury and length of education at follow-up. An additional linear regression analysis was performed with main indexes and composite scores from BRIEF-A and ASR as dependent variables and the presence of TAI employed as a covariate 
TABLE 2: Description of participants: demographics, injury severity characteristics, and clinical observations at 1 and 2-5 years after moderate and severe TBI: global outcome and employment.

\begin{tabular}{|c|c|c|c|c|c|}
\hline Variable & $n$ & Persons with TBI & $n$ & Controls & $p$ value \\
\hline \multicolumn{6}{|l|}{ Demographics at injury } \\
\hline Male sex $(n, \%)$ & 67 & $48(72)$ & 72 & $55(76)$ & $0.593^{*}$ \\
\hline Age (mean, range) & 67 & $29(15-63)$ & & & \\
\hline \multicolumn{6}{|l|}{ Injury-related variables } \\
\hline Mechanisms of injury & 67 & & & & \\
\hline Traffic accident $(n, \%)$ & & $33(49)$ & & & \\
\hline Fall $(n, \%)$ & & $27(40)$ & & & \\
\hline Ski accident $(n, \%)$ & & $2(3)$ & & & \\
\hline Other $(n, \%)$ & & $5(9)$ & & & \\
\hline GCS score (median, IQR) & 67 & $9(7)$ & & & \\
\hline HISS grade; moderate TBI $(n, \%)$ & 67 & $39(58)$ & & & \\
\hline PTA <1 week $(n, \%)$ & 66 & $37(55)$ & & & \\
\hline Early MRI findings & 65 & & & & \\
\hline $\mathrm{EDH}$ only $(n, \%)$ & & $1(2)$ & & & \\
\hline Pure TAI $(n, \%)$ & & $17(25)$ & & & \\
\hline Cortical contusions $(n, \%)$ & & $16(24)$ & & & \\
\hline Cortical contusions/TAI $(n, \%)$ & & $30(45)$ & & & \\
\hline \multicolumn{6}{|l|}{ Global outcome 12 months after injury } \\
\hline GOSE score (median, IQR) & 66 & $7.0(2)$ & & & \\
\hline \multicolumn{6}{|l|}{ Demographics at follow-up } \\
\hline Age (mean, range) & 67 & $32(17-65)$ & 72 & $33(13)$ & $0.683^{\dagger}$ \\
\hline Years after injury (mean, SD) & 67 & 2.90 .8 & & & \\
\hline Years education (mean, range) & 67 & $12(9-18)$ & 72 & $12(2)$ & $0.979^{\dagger}$ \\
\hline Occupation & 67 & & 72 & & $0.025^{\ddagger}$ \\
\hline Unemployed/no school ( $n, \%)$ & & $12(18)$ & & $4(6)$ & \\
\hline Employed or at school $(n, \%)$ & & $55(82)$ & & $68(94)$ & \\
\hline
\end{tabular}

GCS: Glasgow Coma Scale; GOSE: Glasgow Outcome Scale Extended; IQR: interquartile range; PTA: posttraumatic amnesia; SD: standard deviation; TAI: traumatic axonal injury; TBI: Traumatic Brain Injury.

* Pearson's Chi-squared test.

${ }^{\dagger}$ Independent samples $t$-test.

${ }^{\ddagger}$ Unconditional $z$-pooled test.

with adjustment for BDI. Pearson's correlation coefficient $(r)$ was used to analyse associations between the main indexes on BRIEF-A and the symptom scales on ASR.

\section{Results}

Participant characteristics are presented in Table 2 for the full sample and in Table 7 for the subsample. Individuals with TBI and healthy controls did not differ regarding distribution of sex, age at testing, or years of education. Participants with TBI assessed at 3 months after injury exhibited significantly lower estimated IQ and reduced processing speed, memory, and executive function compared with controls. At 2-5 years after injury a higher proportion of individuals with TBI neither worked nor attended school (18\%) compared with controls (6\%, difference in proportions: $12 \% ; p=0.03)$.

3.1. Self-Reported Executive Function 2-5 Years after Injury. Individuals with TBI reported more problems on all three composite indexes of BRIEF-A (GEC, BRI, and MI) than healthy controls (Table 3). Effect sizes were in the moderate range (0.38-0.66). More respondents with TBI $(18 \%)$ reported symptoms in the clinical range on the GEC (difference in proportions; $17 \%, p<0.001$ ), BRI ( $8 \%$; difference in proportions, $7 \% ; p=0.02)$, and MI (20\%; difference in proportions, $18 \%$; $p<0.001)$. On the BRI subscales, participants with TBI also reported more difficulties with inhibition, set-shifting, emotional regulation, and self-monitoring, with effect sizes in the medium range. On the MI subscales, individuals with TBI reported more problems with working memory than healthy controls, with $37 \%$ reporting working memory problems in the clinical range (difference in proportions, $32 \%$; $p<0.001)$.

3.2. Emotional and Behavioural Outcome 2-5 Years after TBI. On the ASR adaptive scales, respondents with TBI reported significantly fewer personal strengths than healthy controls. They did not differ from controls with regard to problems in their family relationships or friendships. On the composite scales Total problems, Internalizing problems, and 
TABLE 3: Self-reported executive function on BRIEF-A at 2-5 years after moderate and severe Traumatic Brain Injury compared to healthy controls*.

\begin{tabular}{|c|c|c|c|c|c|c|}
\hline \multirow[t]{2}{*}{ BRIEF-A ( $T$-scores) } & \multicolumn{2}{|c|}{$\begin{array}{c}\text { Persons with TBI } \\
n=67\end{array}$} & \multicolumn{2}{|c|}{$\begin{array}{c}\text { Controls } \\
n=72\end{array}$} & \multirow{2}{*}{$\begin{array}{c}\text { Mann-Whitney test } \\
\text { p value }\end{array}$} & \multirow{2}{*}{$\begin{array}{l}\text { Effect size } \\
\qquad d^{\dagger}\end{array}$} \\
\hline & Mean & SD & Mean & SD & & \\
\hline \multicolumn{7}{|l|}{ Global scales } \\
\hline Global Executive Composite (GEC) & 51.40 & $(11.94)$ & 46.19 & $(7.28)$ & 0.003 & 0.53 \\
\hline Behaviour regulation Index (BRI) & 50.69 & $(11.13)$ & 44.51 & $(7.28)$ & $<0.001$ & 0.66 \\
\hline Metacognitive Index (MI) & 51.81 & $(11.90)$ & 48.02 & $(7.57)$ & 0.029 & 0.38 \\
\hline \multicolumn{7}{|c|}{ Behavioural and emotional regulation scales } \\
\hline Inhibit & 51.84 & $(10.57)$ & 47.72 & $(8.87)$ & 0.014 & 0.42 \\
\hline Shift & 49.52 & $(11.04)$ & 44.64 & $(7.01)$ & 0.003 & 0.53 \\
\hline Emotional regulation & 51.61 & $(11.45)$ & 44.88 & $(7.81)$ & $<0.001$ & 0.69 \\
\hline Self-Monitor & 47.87 & $(10.70)$ & 44.54 & $(7.74)$ & 0.039 & 0.36 \\
\hline \multicolumn{7}{|l|}{ Metacognitive Index Scales } \\
\hline Initiate & 51.87 & $(11.68)$ & 48.61 & $(9.86)$ & 0.079 & 0.30 \\
\hline Working Memory & 57.48 & $(13.01)$ & 47.89 & $(7.91)$ & $<0.001$ & 0.89 \\
\hline Plan/Organize & 50.54 & $(11.00)$ & 47.61 & $(7.45)$ & 0.071 & 0.31 \\
\hline Task Monitoring & 50.97 & $(11.90)$ & 48.88 & $(7.27)$ & 0.217 & 0.21 \\
\hline Organization of Materials & 46.60 & $(11.54)$ & 48.49 & $(8.35)$ & 0.268 & -0.19 \\
\hline
\end{tabular}

Higher $T$-scores indicate more problems.

${ }^{*}$ Central tendency and variance given as mean and $\mathrm{SD}$.

${ }^{\dagger}$ Cohen's $d$.

SD: standard deviation.

Externalizing problems, persons with TBI reported significantly more problems compared with controls (Table 4). Effect sizes were in the medium range (0.40-0.68). A greater proportion of individuals with TBI $(20 \%)$ reported problems in the clinical range on the scales Total problems (difference in proportions, $18 \% ; p=0.002$ ), Internalizing problems (24\%; difference in proportions, $16 \% ; p=0.05$ ), and Externalizing problems (14\%; difference in proportions, $12 \%$; $p=0.016)$. On the syndrome scales, individuals with TBI also reported more problems with anxiousness/depression, somatic complaints, thought problems, attention problems, and aggressive behaviour than healthy controls. Among the DSM-IV-oriented scales, respondents with TBI reported higher scores for depression, anxiety, somatic problems, and attention problems. They also reported higher scores than controls on critical items $(d: 0.84)$.

3.3. Factors Associated with Executive, Emotional, and Behavioural Problems at Follow-Up. Fewer years of education predicted endorsement of greater problems on the GEC and BRI, but not on the MI (Table 5). TAI on MRI during the early phase predicted more problems on GEC and BRI, while GCS score and duration of PTA did not. However, the association between TAI and the GEC and BRI did not reach statistical significance when adjusted for age and education. Neuropsychological test performance at 3 months after injury was not associated with any of the BRIEF-A scales ( $\beta$ ranging from -0.187 to $0.137, p>0.05$ for all; see Table 8 for full overview). Depressive symptoms at 3 months after injury predicted metacognitive problems (MI) at follow-up, while depressive symptoms 1 year after injury predicted later executive problems on all the main indexes. Lower GOSE score at 12 months after injury predicted more problems on all main indexes at follow-up.

Younger age at injury predicted more emotional and behavioural problems at follow-up, particularly regarding Externalizing problems (Table 6). Presence of TAI on early MRI predicted higher scores on ASR Total problems and Internalizing problems. Only the association with Internalizing problems persisted after adjusting for age at injury and length of education. However, the presence of TAI still predicted higher scores on ASR Total problems and Internalizing problems, when adjusting for depressive symptoms 3 months after injury. More depressive symptoms at both 3 and 12 months after injury predicted later high scores on ASR Total problems, and depressive symptoms 12 months after injury predicted both Internalizing and Externalizing problems at follow-up.

Lower GOSE score at 12 months after injury predicted later high scores on both ASR Total problems and Internalizing problems when adjusted for age and education. Neuropsychological test performance at 3 months after injury was not associated with any of the ASR scales ( $\beta$ ranging from -0.086 to $0.588, p>0.05$ for all; see Table 8 for full overview).

Concurrent status of employment was not associated with any main BRIEF-A index or ASR composite score ( $\beta$ : -5.151 to $2.954, p>0.05$ for all). Patients that reported more problems on the ASR symptom scales also reported more problems on the GEC, with correlation coefficients ranging from 0.327 (thought problems) to 0.823 (attention problems; $p<0.001$ 
TABLE 4: Self-reported adaptive function, personal strengths, and psychological problems on ASR at 2-5 years after moderate and severe Traumatic Brain Injury compared to healthy controls.

\begin{tabular}{|c|c|c|c|c|c|c|c|c|}
\hline \multirow[t]{2}{*}{ Adult Self-Report } & \multicolumn{2}{|c|}{$\begin{array}{c}\text { Persons with TBI } \\
\quad n=66\end{array}$} & \multicolumn{2}{|c|}{$\begin{array}{c}\text { Controls } \\
n=71\end{array}$} & \multicolumn{2}{|c|}{$\begin{array}{c}\text { Mean difference } \\
(95 \% \mathrm{CI})^{\dagger}\end{array}$} & \multirow{2}{*}{$\begin{array}{c}t \text {-test } \\
p\end{array}$} & \multirow{2}{*}{$\begin{array}{c}\text { Effect size } \\
\qquad d^{\ddagger}\end{array}$} \\
\hline & Mean & SD & Mean & SD & Lower & Upper & & \\
\hline \multicolumn{9}{|l|}{ Adaptive scores* } \\
\hline Personal strengths & 16.18 & $(3.18)$ & 17.39 & $(3.09)$ & -2.26 & -0.15 & 0.025 & 0.39 \\
\hline Mean adaptive & 49.61 & $(5.44)$ & 50.15 & $(4.32)$ & -2.21 & 1.13 & 0.523 & 0.11 \\
\hline Relation to friends & 9.82 & $(2.00)$ & 10.00 & $(1.82)$ & -0.82 & 0.46 & 0.580 & 0.09 \\
\hline Relation to family & 1.57 & $(0.44)$ & 1.49 & $(0.37)$ & -0.06 & 0.22 & 0.246 & -0.20 \\
\hline \multicolumn{9}{|l|}{ Composite scales } \\
\hline Total problems & 39.17 & $(26.08)$ & 26.13 & $(16.67)$ & 5.57 & 20.51 & 0.001 & 0.60 \\
\hline Internalizing problems & 12.44 & $(9.81)$ & 7.08 & $(5.42)$ & 2.64 & 8.07 & $<0.001$ & 0.68 \\
\hline Externalizing problems & 9.05 & $(8.59)$ & 6.24 & $(5.05)$ & 0.40 & 5.22 & 0.023 & 0.40 \\
\hline Critical items & 4.95 & $(3.64)$ & 2.46 & $(2.22)$ & 1.46 & 3.52 & $<0.001$ & 0.83 \\
\hline \multicolumn{9}{|l|}{ Syndrome scales } \\
\hline Anxious/depressed & 6.48 & $(6.29)$ & 3.34 & $(3.26)$ & 1.43 & 4.87 & $<0.001$ & 0.63 \\
\hline Withdrawn & 2.27 & $(2.22)$ & 1.75 & $(1.93)$ & -0.17 & 1.27 & 0.139 & .25 \\
\hline Somatic complaints & 3.68 & $(2.81)$ & 2.00 & $(2.08)$ & 0.84 & 2.52 & $<0.001$ & 0.68 \\
\hline Thought problems & 2.09 & $(2.26)$ & 1.01 & $(2.25)$ & 0.31 & 1.84 & 0.006 & 0.48 \\
\hline Attention problems & 7.73 & $(5.37)$ & 4.96 & $(3.72)$ & 1.19 & 4.32 & 0.001 & 0.60 \\
\hline Aggressive behaviour & 4.76 & $(4.55)$ & 2.01 & $(2.46)$ & 1.49 & 4.00 & $<0.001$ & 0.75 \\
\hline Rule-breaking behaviour & 2.70 & $(3.49)$ & 2.21 & $(2.12)$ & -0.50 & 1.47 & 0.331 & 0.17 \\
\hline Intrusive behaviour & 1.59 & $(1.96)$ & 2.01 & $(1.89)$ & -1.07 & 0.23 & 0.200 & -0.22 \\
\hline \multicolumn{9}{|l|}{ DSM-IV oriented scales } \\
\hline Depression & 5.02 & $(4.52)$ & 2.70 & $(2.47)$ & 1.06 & 3.56 & $<0.001$ & 0.64 \\
\hline Anxiety & 3.12 & $(2.67)$ & 2.00 & $(2.00)$ & 0.32 & 1.92 & 0.007 & 0.47 \\
\hline Somatic & 2.21 & $(2.17)$ & 1.30 & $(1.57)$ & 0.28 & 1.55 & 0.005 & 0.48 \\
\hline Avoidant personality problems & 2.32 & $(2.02)$ & 2.11 & $(1.88)$ & -0.45 & 0.86 & 0.538 & 0.11 \\
\hline ADHD problems & 7.20 & $(4.86)$ & 4.85 & $(3.69)$ & 0.88 & 3.82 & 0.002 & 0.54 \\
\hline Inattention & 3.88 & $(2.81)$ & 2.37 & $(2.10)$ & 0.67 & 2.36 & 0.001 & 0.61 \\
\hline Hyperactivity/impulsivity & 3.32 & $(2.53)$ & 2.48 & $(2.21)$ & 0.04 & 1.64 & 0.040 & 0.35 \\
\hline Antisocial personality problems & 3.50 & $(4.44)$ & 2.66 & $(2.73)$ & -0.41 & 2.11 & 0.182 & 0.23 \\
\hline
\end{tabular}

Central tendency and variance measured in mean and SD (raw scores). Higher scores indicate more problems.

${ }^{*}$ Higher scores indicate better function

${ }^{\dagger}$ Results from $t$-test based on 2000 bootstrap samples.

${ }^{\ddagger}$ Cohen's $d$.

ADHD: attention deficit and hyperactivity disorder, CI: confidence interval, DSM-IV: Diagnostic and Statistical Manual of Mental Disorders, 4th edition, and SD: standard deviation.

for all). This pattern held true also for the indexes BRI ( $r$ : from 0.242 to $0.716, p<0.01$ for all) and MI ( $r: 0.283$ to 0.816 , $p<0.001$ for all). An exception was ASR intrusive behaviour, which was associated only with BRI $(r: 0.27, p=0.027)$, and not with GEC ( $r: 0.20, p=0.112)$ or MI $(r: 0.12, p=0.319$; see Table 9 for full overview).

\section{Discussion}

In this large, prospective longitudinal study, our main aim was to delineate the magnitude and profile of chronic problems with executive, emotional, and behavioural function experienced by individuals with moderate-to-severe TBI 2-5 years after injury. As we hypothesised, greater overall selfreported executive problems were found among persons with TBI compared with healthy controls. This was evident both in terms of group differences and the frequency of individuals reporting problems in the clinical range. Further, persons with TBI significantly more often reported feeling sad or depressed compared with healthy controls. However, group differences in emotional and behavioural problems did not always indicate symptoms above the clinical cutoff, supporting emerging findings within the paediatric TBI population [79]. This observation suggests that subclinical executive problems are commonly experienced within the group as a whole, which may add to the total symptom burden for individuals with TBI. 


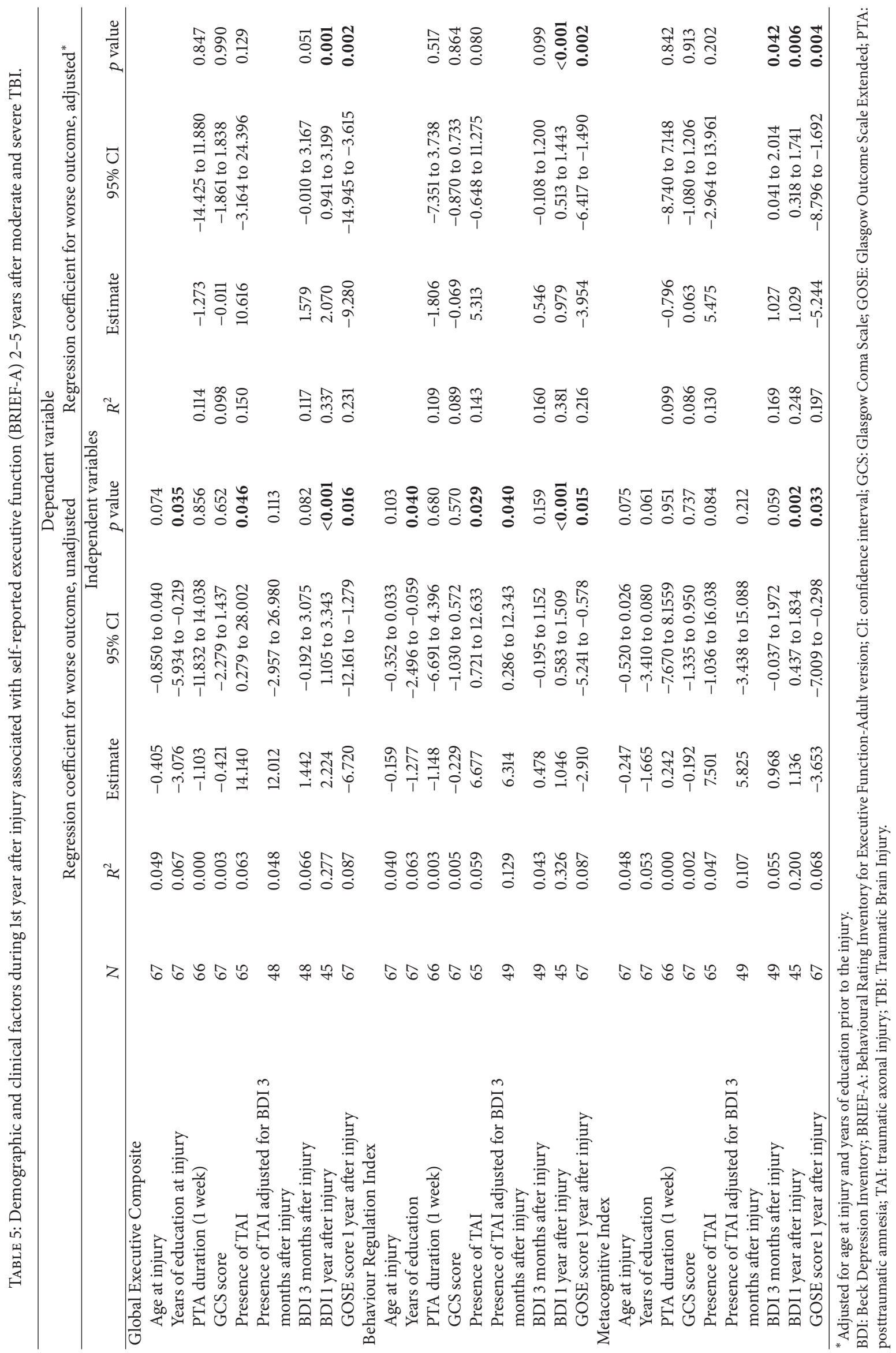




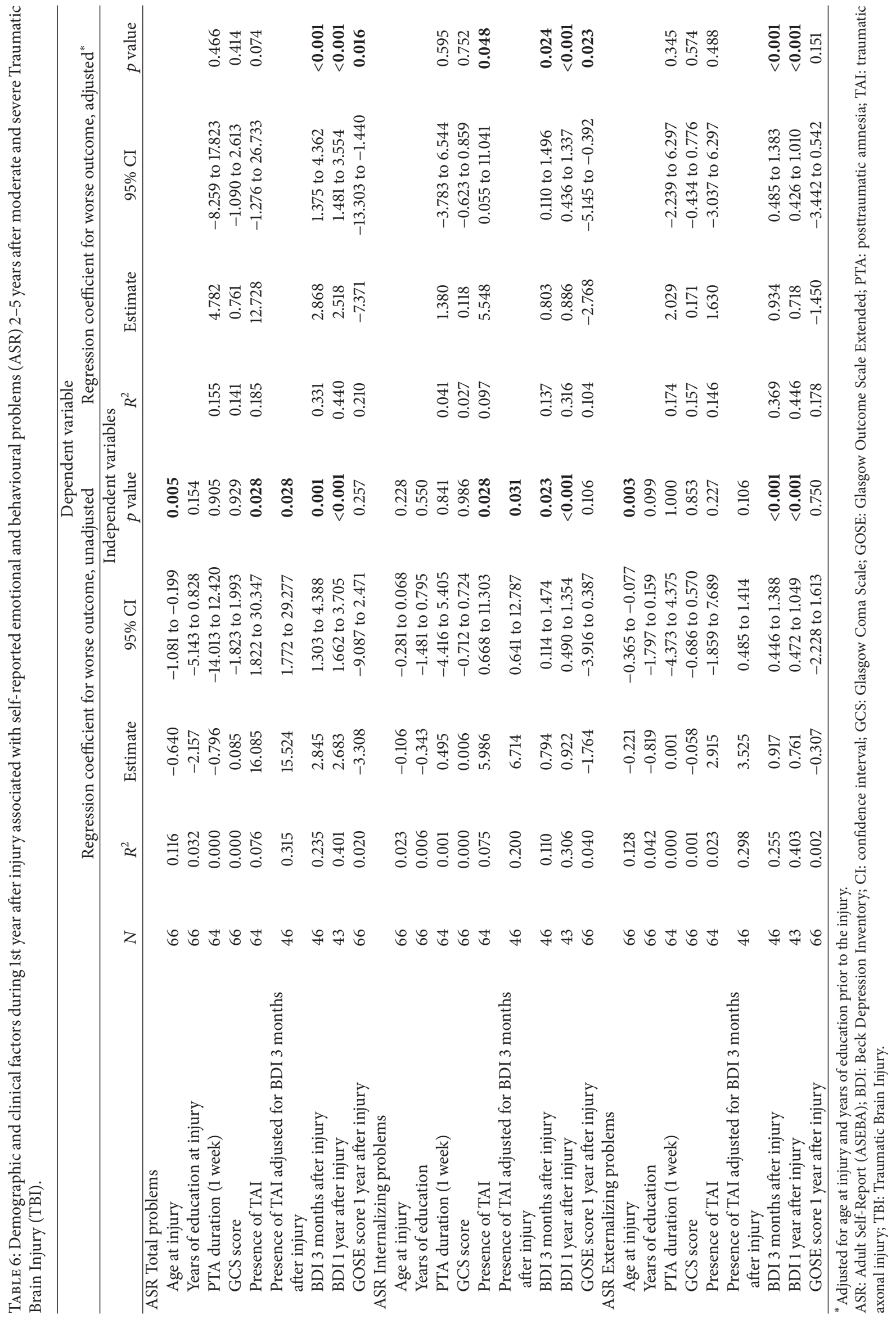


TABLE 7: Description of participants in the subgroup analysis: demographics, injury severity characteristics, and clinical observations at 3 months, 1 year, and 2-5 years after moderate and severe TBI: cognitive function, emotional function, global outcome, and employment.

\begin{tabular}{|c|c|c|c|c|c|}
\hline Variable & $n$ & Persons with TBI & $n$ & Controls & $p$ value \\
\hline \multicolumn{6}{|l|}{ Demographics } \\
\hline Male sex $(n, \%)$ & 49 & $35(71)$ & 28 & $24(86)$ & $0.593^{*}$ \\
\hline Age at injury (mean, range) & 49 & $30(14-63)$ & & & \\
\hline \multicolumn{6}{|l|}{ Injury-related variables } \\
\hline GCS score (median, IQR) & 49 & $9(6)$ & & & \\
\hline HISS grade; moderate TBI $(n, \%)$ & 49 & $28(57)$ & & & \\
\hline PTA $<1$ week $(n, \%)$ & 48 & $23(47)$ & & & \\
\hline Early MRI findings & 48 & & & & \\
\hline $\mathrm{EDH}$ only $(n, \%)$ & & $1(2)$ & & & \\
\hline Pure TAI $(n, \%)$ & & $10(20)$ & & & \\
\hline Cortical contusions $(n, \%)$ & & $14(29)$ & & & \\
\hline Cortical contusions/TAI $(n, \%)$ & & $23(48)$ & & & \\
\hline \multicolumn{6}{|l|}{ Neuropsychological assessment ( 3 months after injury) } \\
\hline Days after injury (mean, SD) & 49 & $99(10)$ & & & \\
\hline Estimated IQ (mean, SD) & 47 & $106(16)$ & 26 & $119(12)$ & $0.001^{\dagger}$ \\
\hline Processing speed (mean, SD) & 46 & $44.5(10.2)$ & 26 & $53.0(4.8)$ & $<0.001^{\dagger}$ \\
\hline Attention (mean, SD) & 46 & $49.9(4.9)$ & 26 & $51.6(4.3)$ & $0.124^{\dagger}$ \\
\hline Memory (mean, SD) & 46 & $42.6(10.0)$ & 26 & $48.2(8.3)$ & $0.016^{\dagger}$ \\
\hline Executive function (mean, SD) & 47 & $47.3(7.6)$ & 26 & $53.1(4.8)$ & $0.001^{\dagger}$ \\
\hline \multicolumn{6}{|c|}{ Depressive symptoms and global outcome 1st year after injury } \\
\hline BDI 3 months after injury (mean, SD) & 47 & $5.5(4.4)$ & & & \\
\hline BDI 12 months after injury (mean, SD) & 44 & $6.7(6.4)$ & & & \\
\hline GOSE score 12 months after injury (median, IQR) & 49 & $7.0(2)$ & & & \\
\hline \multicolumn{6}{|l|}{ Demographics at follow-up } \\
\hline Years after injury (mean, SD) & 49 & 3.21 .0 & & & \\
\hline Age (mean, range) & 49 & $34(17-65)$ & 28 & $34(19-64)$ & $0.895^{\dagger}$ \\
\hline Years education (mean, range) & 49 & $12(9-18)$ & 28 & $12(9-18)$ & $0.630^{\dagger}$ \\
\hline Occupation & 49 & & 27 & & \\
\hline Unemployed/no school ( $n, \%)$ & & $10(20)$ & & $1(4)$ & \\
\hline Employed or at school $(n, \%)$ & & $55(82)$ & & $26(96)$ & \\
\hline
\end{tabular}

GCS: Glasgow Coma Scale; GOSE: Glasgow Outcome Scale Extended; IQ: Intelligence Quotient; IQR: interquartile range; PTA: posttraumatic amnesia; SD: standard deviation; TAI: traumatic axonal injury; TBI: Traumatic Brain Injury.

${ }^{*}$ Pearson's Chi-squared test.

${ }^{\dagger}$ Independent samples $t$-test.

Our study demonstrated that self-reported problems with working memory, attentional control, and monitoring ongoing operations were frequently reported among persons sustaining TBI in adolescence and adulthood, which adds to the findings in studies utilizing similar tools in populations with other neurological deficits $[29,80,81]$. We also observed that participants with TBI experienced significantly more problems with inhibition, mental flexibility, and emotional regulation, which adds to existing literature on adult/adolescent TBI populations applying the same assessment tools and has not been reported in previous studies. Contrary to our expectations, problem-solving, initiation, and task monitoring were not perceived as problematic among individuals with TBI in our study, which is in contrast to a study comprising moderate and severe TBI survivors, where these functions were perceived as most problematic [30]. However, the few studies that have employed the BRIEF-A as an outcome measure after TBI sustained in late adolescence and adulthood have had relatively small sample sizes [29, 30, 82], been retrospective in design [29, 83], and lacked comparisons with large demographically matched healthy control groups. We may speculate that by addressing these methodological issues our study revealed significant differences in self-reported problems within several areas of executive function after TBI previously not highlighted as problematic for this population.

While the presence of aggressive behaviour across the entire TBI group is in line with the literature reviewing longterm psychiatric outcome after TBI $[13,25]$, in our study, they did not report more rule-breaking behaviour (lack of empathy, substance abuse, and law-breaking behaviour) or intrusive behaviour. The aggression scale on ASR consists of several items related to behavioural control, and we speculate that executive problems (e.g., impaired inhibition 
TABLE 8: Associations between main composite scores on BRIEF-A and ASR 2-5 years after moderate and severe TBI and neuropsychological test performance 3 months after injury*.

\begin{tabular}{|c|c|c|c|c|c|}
\hline & & & \multicolumn{3}{|c|}{$\begin{array}{c}\text { Dependent variable } \\
\text { Regression coefficient for worse outcome }\end{array}$} \\
\hline & \multicolumn{5}{|c|}{ Independent variable } \\
\hline & $N$ & $R^{2}$ & Estimate & $95 \%$ confidence interval & $p$ value \\
\hline \multicolumn{6}{|l|}{ BRIEF-A GEC } \\
\hline Processing speed & 47 & 0.015 & -0.143 & -0.492 to 0.205 & 0.413 \\
\hline Attention & 47 & 0.001 & -0.077 & -0.831 to 0.678 & 0.839 \\
\hline Memory & 46 & 0.008 & 0.112 & -0.268 to 0.491 & 0.556 \\
\hline Executive function & 48 & 0.012 & -0.167 & -0.626 to 0.291 & 0.467 \\
\hline \multicolumn{6}{|l|}{ BRIEF-A BRI } \\
\hline Processing speed & 47 & 0.015 & -0.138 & -0.470 to 0.194 & 0.408 \\
\hline Attention & 47 & 0.006 & -0.187 & -0.887 to 0.513 & 0.594 \\
\hline Memory & 46 & 0.004 & 0.074 & -0.285 to 0.433 & 0.679 \\
\hline Executive function & 48 & 0.011 & -0.155 & -0.592 to 0.281 & 0.478 \\
\hline \multicolumn{6}{|l|}{ BRIEF-A MI } \\
\hline Processing speed & 47 & 0.010 & -0.115 & -0.454 to 0.224 & 0.497 \\
\hline Attention & 47 & 0.000 & 0.011 & -0.723 to 0.745 & 0.976 \\
\hline Memory & 46 & 0.013 & 0.137 & -0.225 to 0.500 & 0.449 \\
\hline Executive function & 48 & 0.009 & -0.146 & -0.591 to 0.299 & 0.513 \\
\hline \multicolumn{6}{|l|}{ ASR Total problems } \\
\hline Processing speed & 46 & 0.000 & 0.059 & -0.753 to 0.872 & 0.883 \\
\hline Attention & 46 & 0.000 & 0.065 & -1.627 to 1.756 & 0.939 \\
\hline Memory & 46 & 0.046 & 0.588 & -0.229 to 1.405 & 0.154 \\
\hline Executive function & 47 & 0.002 & 0.145 & -0.933 to 1.223 & 0.788 \\
\hline \multicolumn{6}{|c|}{ ASR Internalizing problems } \\
\hline Processing speed & 46 & 0.010 & 0.106 & -0.209 to 0.421 & 0.501 \\
\hline Attention & 46 & 0.000 & 0.043 & -0.620 to 0.705 & 0.897 \\
\hline Memory & 46 & 0.060 & 0.260 & -0.054 to 0.575 & 0.102 \\
\hline Executive function & 47 & 0.008 & 0.126 & -0.291 to 0.543 & 0.545 \\
\hline \multicolumn{6}{|c|}{ ASR Externalizing problems } \\
\hline Processing speed & 46 & 0.001 & -0.033 & -0.291 to 0.225 & 0.798 \\
\hline Attention & 46 & 0.002 & -0.086 & -0.628 to 0.456 & 0.750 \\
\hline Memory & 46 & 0.020 & 0.125 & -0.138 to 0.388 & 0.344 \\
\hline Executive function & 47 & 0.000 & 0.024 & -0.318 to 0.367 & 0.887 \\
\hline
\end{tabular}

* Given in $T$-scores.

BRI: Behaviour Regulation Index, GEC: Global Executive Composite, MI: Metacognitive Index, and TBI: Traumatic Brain Injury.

TABLE 9: Associations between main indexes on BRIEF-A and symptom scales on ASR at 2-5 years after moderate and severe TBI.

\begin{tabular}{|c|c|c|c|c|c|c|}
\hline \multirow[t]{2}{*}{ ASR symptom scales } & \multicolumn{2}{|c|}{$\begin{array}{c}\text { BRIEF-A } \\
\text { Global Executive Composite (GEC) }\end{array}$} & \multicolumn{2}{|c|}{$\begin{array}{c}\text { BRIEF-A } \\
\text { Behaviour Regulation Index (BRI) }\end{array}$} & \multicolumn{2}{|c|}{$\begin{array}{c}\text { BRIEF-A } \\
\text { Metacognitive Index (MI) }\end{array}$} \\
\hline & $r$ & $p$ value & $r$ & $p$ value & $r$ & $p$ value \\
\hline Anxious/depressed & 0.75 & $<0.001$ & 0.70 & $<0.001$ & 0.72 & $<0.001$ \\
\hline Withdrawn & 0.59 & $<0.001$ & 0.55 & $<0.001$ & 0.57 & $<0.001$ \\
\hline Somatic complaints & 0.51 & $<0.001$ & 0.50 & $<0.001$ & 0.47 & $<0.001$ \\
\hline Thought problems & 0.44 & $<0.001$ & 0.43 & $<0.001$ & 0.41 & 0.001 \\
\hline Attention problems & 0.86 & $<0.001$ & 0.77 & $<0.001$ & 0.83 & $<0.001$ \\
\hline Aggressive behaviour & 0.62 & $<0.001$ & 0.72 & $<0.001$ & 0.49 & $<0.001$ \\
\hline Rule-breaking behaviour & 0.44 & $<0.001$ & 0.40 & 0.001 & 0.43 & $<0.001$ \\
\hline Intrusive behaviour & 0.20 & 0.112 & 0.27 & 0.027 & 0.12 & 0.319 \\
\hline
\end{tabular}

ASR: Adult Self-Report; BRIEF-A: Behaviour Rating Inventory of Executive Function-Adult version. 
and reduced task monitoring/switching) [15] may mediate the behavioural and emotional problems experienced by individuals after TBI [25]. Further, excessive mood swings were commonly reported, which may indicate an increased risk of psychiatric diagnoses [59]. Controlling emotional and behavioural expression is also important for social and occupational functioning [84]. However, our respondents with TBI did not report more social withdrawal or problems with social relations, which is in contrast to previous studies $[9,85]$. It could be argued that the persons with TBI may have underestimated their social problems, but the substantial proportion of moderate TBI in our study may reduce the risk of underreporting problems due to problems with selfawareness [86]. Another possibility is that this measure may not be sensitive enough to pick up underlying relationship problems. However, the health care system in Norway provides early access to treatment and rehabilitation services, including family support interventions. Whether such access to early intervention may contribute to participants reporting less social problems compared to findings from previous studies should be investigated further in future research. Nevertheless, our finding illustrates that the persons with TBI were less concerned about relationship problems compared to problems with regulating their emotions and behaviour, which suggests that this area is an important target in postTBI rehabilitation.

4.1. Factors Associated with Self-Reported Executive, Behavioural, and Emotional Problems. Our second aim was to explore the effects of demographic, injury-related, psychological, neuropsychological, and global outcome factors, as obtained in the postacute phase, on later self-reported problems. Firstly, we hypothesised that the measures of injury severity were associated with later long-term outcome. Extending previous studies, our results suggest that TAI plays a contributing role in the development of self-reported Internalizing problems (e.g., anxiety and depression) and behaviour regulation. This association persisted even after adjusting for early self-reported depressive symptoms. TAI is a microscopic strain injury of axons and blood vessels in different predilection locations of the brain, typically causing widespread damage often localized in frontotemporal and subcortical structures [87], also affecting subcortical structures with frontal projections $[3,88]$. The same neuropathological changes may also affect the development of mood disorders [52]. In combination with the unexpected findings that other measures of injury severity were not associated with later self-reported problems [39], this suggests that the pathophysiological processes associated with TAI may have a distinct effect on later perceived problems with emotional and behavioural regulation as long as $2-5$ years after injury. No previous study has investigated associations between long-term self-reported executive, emotional and behavioural function, and presence of TAI detected by clinical MRI in the early phase, and our findings suggest that neurological imaging in the early phase after TBI may aid in identifying persons at risk of poorer long-term outcome.

As hypothesised, we found that self-reported symptoms of depression within the first year after injury predicted later perceived overall problems with goal-directed cognitive and behavioural regulation, in addition to Externalizing and Internalizing problems. These findings support previous studies showing that emotional distress affects the extent of self-reported cognitive problems $[29,55]$. However, adaptive problems in every-day life due to impairments after TBI in combination with the negative thinking typically experienced during depression [89] may contribute to the long-term self-reported depressive symptoms found in our study. This illustrates the importance of identifying, monitoring, and possibly treating depressive symptoms early in the course after TBI.

Further, younger age at injury predicted more selfreported Externalizing problems in the longer-term postTBI, which is in accordance with previous studies that employed methods of retrospective assessment [12] or cluster analysis [26]. While we found that fewer years of education were associated with more self-reported problems with goaldirected cognitive and behavioural regulation, no association was found with self-reported aggressive behaviour. This is in contrast to other reports which have indicated that more years of education and higher socioeconomic status are associated with lesser endorsement of behavioural problems [26]. The aggressive behaviour in participants who were younger at the time of injury could be explained by the increased vulnerability to injury in rapidly developing brain areas [90]. The frontal lobe is still maturing during adolescence and young adulthood, rendering functions located therein (e.g., emotional and behavioural regulation) at increased risk following injury [91]. Furthermore, age was not associated with symptoms of depression, anxiety, or somatic complaints among individuals with TBI. Some have suggested the presence of distinct pathways and risk factors in the development of depression and anxiety as opposed to aggression [26], and we speculate that our findings might be in line with this. Our results indicate a need for future research to examine the possible differences in long-term outcome for persons injured in adolescence compared to those sustaining a TBI in adulthood.

We hypothesised that both global function and neuropsychological performance within the first year after injury would be associated with outcome 2-5 years after TBI. As expected, reduced global outcome one year after injury was associated with more reported executive and Internalizing problems. Experiencing reduced global function, including less ability to resume social relationships or leisure activities, may lead to a negative self-image and the increased endorsement of problems. However, the reported executive problems may also reflect cognitive impairment caused by the injury. Contrary to what we hypothesised, we observed no association between performance-based measures of cognitive function three months after injury and later self-reported executive, emotional, and behavioural function. This is in contrast to other studies demonstrating associations between performance-based and self-reported measures of task monitoring and switching $[29,30]$. The lack of convergence among the data may be explained by different modes of measurement [92]. Our findings support the notion that self-reported cognitive complaints are affected by emotional symptoms 
$[21,29,93]$, compared to performance-based measures of executive function which as previous studies suggest are more closely linked to neural damage after TBI [21, 29, 47]. Taken together, this may suggest that performance-based executive function may better reflect the efficacy of processing (optimal performance) as supported by the underlying brain structure [19], whereas self-reported executive function is rather related to adaptive functional changes in the brain $[47,48]$, possibly developing over time as a consequence of the initial injury and/or cognitive problems. Given the multifaceted and complex nature of executive dysfunction after TBI, further validation of both performance-based and self-report measures of executive function is needed.

4.2. Clinical Implications. By assessing self-reported executive, emotional, and behavioural long-term outcome, our study revealed that the persons with TBI experienced subjective problems that were not detected with, for instance, neuropsychological tests, illustrating the importance of including self-evaluation inventories in addition to tests. Our results indicate that detection of DAI on early MRI and assessment of self-reported symptoms of depression within the first year after injury can aid in identifying persons at risk of experiencing poorer executive, emotional, and behavioural longterm outcome. This can be used for more targeted and cost efficient rehabilitation. Furthermore, psychological and/or pharmaceutical interventions, with a focus on depressive symptomatology, may be helpful in reducing the long-term problems experienced by persons sustaining a TBI and lessen their overall symptom burden. In addition, the results suggest that age is a notable risk factor for development of aggressive behaviour, and initiating interventions targeting this should be part of the rehabilitation of adolescence sustaining TBI.

4.3. Study Limitations. Our main aim was to explore longterm change in self-reported executive, emotional, and behavioural function after moderate and severe TBI sustained in adolescence as well as in adulthood, which also guided the development of the study design. The reliance on self-report forms may limit transferral to studies applying performancebased neuropsychological tests or diagnostic interviews and makes our study less optimal for exploring the validity of the BRIEF-A and ASR as proxies for cognitive function and psychiatric diagnoses. Performance-based measures were available for only the subgroup that consented to participate in both the neuropsychological study and the long-term follow-up study. Due to this design, the findings should be interpreted with caution.

\section{Conclusion}

Persons with moderate and severe TBI reported significantly more pronounced difficulties in aspects of executive functions related to attentional control, working memory, and emotional regulation, as well as emotional and behavioural problems related to symptoms of depression, anxiety, and aggressive behaviour 2-5 years after injury compared to healthy controls. Both the presence of TAI on early MRI and reported symptoms of depression during the first year after injury were important predictors of later self-reported executive, emotional, and behavioural problems. Our findings indicate that demographic, neuropathological, and psychological factors all influence the development of self-reported executive, emotional, and behavioural problems for years after TBI. Our study highlights that early radiological and broad psychological evaluations may give clues as to which patients may be at risk for poorer long-term outcome. In summary, this study yields new information to guide the clinical management of TBI survivors and provides groundwork for additional clinical research regarding the long-term consequences of TBI.

\section{Appendix}

See Figures 1 and 2 and Tables 7, 8, and 9.

\section{Ethical Approval}

The work has been conducted in accordance with the Declaration of Helsinki (1964).

\section{Consent}

Consent has been obtained from persons named in Acknowledgments and from the participants in this study.

\section{Conflict of Interests}

The authors declare that there is no conflict of interests regarding the publication of this paper. There are no financial or other relationships that might lead to a conflict of interests.

\section{Authors' Contribution}

The paper has been approved by all the coauthors.

\section{Acknowledgments}

The authors thank Brit Bjørklimo and neuropsychologists at the Department of Physical Medicine and Rehabilitation, St. Olavs Hospital, for assistance with collection and preparation of the neuropsychological data and Beate Holmqvist Karlsen, Stine B. Lund, and Otto Aarhaug for research assistance and outcome assessment. The authors would also like to thank Alexandra Maria Costache and Gunnar Gotaas for their contribution in data collection and assistance in the process of preprocessing self-report data in the follow-up phase of the project. This work was supported by the Norwegian Extra Foundation for Health and Rehabilitation (first author, Grant no. 2010/2/0105); the Liaison Committee between the Central Norway Regional Health Authority (RHA) and the Norwegian University of Science and Technology (NTNU) (first author, Grant no. 47063700); and SINTEF Unimed Innovation Research Fund (first author, Grant no. 09/9603). The Norwegian research Council, through MI Lab at the Norwegian University of Science and Technology, and 
the National Center of Competence Services for functional MRI, Department of Medical imaging, Trondheim University Hospital, also contributed financially to this project.

\section{References}

[1] K. Draper, J. Ponsford, and M. Schönberger, "Psychosocial and emotional outcomes 10 years following traumatic brain injury," Journal of Head Trauma Rehabilitation, vol. 22, no. 5, pp. 278287, 2007.

[2] L. Himanen, R. Portin, H. Isoniemi, H. Helenius, T. Kurki, and O. Tenovuo, "Longitudinal cognitive changes in traumatic brain injury: a 30-year follow-up study," Neurology, vol. 66, no. 2, pp. 187-192, 2006.

[3] S. Koponen, T. Taiminen, R. Portin et al., "Axis I and II psychiatric disorders after traumatic brain injury: a 30-year follow-up study," The American Journal of Psychiatry, vol. 159, no. 8, pp. 1315-1321, 2002.

[4] E. Lannoo, F. Colardyn, T. Vandekerckhove, C. De Deyne, G. De Soete, and C. Jannes, "Subjective complaints versus neuropsychological test performance after moderate to severe head injury," Acta Neurochirurgica, vol. 140, no. 3, pp. 245-253, 1998.

[5] T. G. Finnanger, T. Skandsen, S. Andersson, S. Lydersen, A. Vik, and M. Indredavik, "Differentiated patterns of cognitive impairment 12 months after severe and moderate traumatic brain injury," Brain Injury, vol. 27, no. 13-14, pp. 1606-1616, 2013.

[6] S. A. Reid-Arndt, C. Nehl, and J. Hinkebein, "The Frontal Systems Behaviour Scale (FrSBe) as a predictor of community integration following a traumatic brain injury," Brain Injury, vol. 21, no. 13-14, pp. 1361-1369, 2007.

[7] G. Spitz, J. L. Ponsford, D. Rudzki, and J. J. Maller, "Association between cognitive performance and functional outcome following traumatic brain injury: a longitudinal multilevel examination," Neuropsychology, vol. 26, no. 5, pp. 604-612, 2012.

[8] M. J. Rapoport, "Depression following traumatic brain injury: epidemiology, risk factors and management," CNS Drugs, vol. 26, no. 2, pp. 111-121, 2012.

[9] J. M. Rogers and C. A. Read, "Psychiatric comorbidity following traumatic brain injury," Brain Injury, vol. 21, no. 13-14, pp. 13211333, 2007.

[10] S. L. West, "Substance use among persons with traumatic brain injury: a review," NeuroRehabilitation, vol. 29, no. 1, pp. 1-8, 2011.

[11] R. Whelan-Goodinson, J. Ponsford, L. Johnston, and F. Grant, "Psychiatric disorders following traumatic brain injury: their nature and frequency," Journal of Head Trauma Rehabilitation, vol. 24, no. 5, pp. 324-332, 2009.

[12] I. J. Baguley, J. Cooper, and K. Felmingham, "Aggressive behavior following traumatic brain injury: how common is common?" Journal of Head Trauma Rehabilitation, vol. 21, no. 1, pp. 45-56, 2006.

[13] D. C. Hesdorffer, S. L. Rauch, and C. A. Tamminga, "Long-term psychiatric outcomes following traumatic brain injury: a review of the literature," Journal of Head Trauma Rehabilitation, vol. 24, no. 6, pp. 452-459, 2009.

[14] T. Ownsworth and K. McKenna, "Investigation of factors related to employment outcome following traumatic brain injury a critical review and conceptual model," Disability and Rehabilitation, vol. 26, no. 13, pp. 765-784, 2004.
[15] A. Miyake, N. P. Friedman, M. J. Emerson, A. H. Witzki, A. Howerter, and T. D. Wager, "The unity and diversity of executive functions and their contributions to complex "Frontal Lobe" tasks: a latent variable analysis," Cognitive Psychology, vol. 41, no. 1, pp. 49-100, 2000.

[16] D. T. Stuss, "Functions of the frontal lobes: relation to executive functions," Journal of the International Neuropsychological Society, vol. 17, no. 5, pp. 759-765, 2011.

[17] P. Malloy and J. Grace, "A review of rating scales for measuring behavior change due to frontal systems damage," Cognitive and Behavioral Neurology, vol. 18, no. 1, pp. 18-27, 2005.

[18] E. M. Warriner and D. Velikonja, "Psychiatric disturbances after traumatic brain injury: neurobehavioral and personality changes," Current Psychiatry Reports, vol. 8, no. 1, pp. 73-80, 2006.

[19] M. E. Toplak, R. F. West, and K. E. Stanovich, "Practitioner Review: do performance-based measures and ratings of executive function assess the same construct?" Journal of Child Psychology and Psychiatry and Allied Disciplines, vol. 54, no. 2, pp. 131-143, 2013.

[20] N. Chaytor and M. Schmitter-Edgecombe, "The ecological validity of neuropsychological tests: a review of the literature on everyday cognitive skills," Neuropsychology Review, vol. 13, no. 4, pp. 181-197, 2003.

[21] D. M. Schiehser, D. C. Delis, J. V. Filoteo et al., "Are self-reported symptoms of executive dysfunction associated with objective executive function performance following mild to moderate traumatic brain injury?" Journal of Clinical and Experimental Neuropsychology, vol. 33, no. 6, pp. 704-714, 2011.

[22] J. Lengenfelder, A. Arjunan, N. Chiaravalloti, A. Smith, and J. Deluca, "Assessing frontal behavioral syndromes and cognitive functions in traumatic brain injury," Applied Neuropsychology: Adult, vol. 22, no. 1, pp. 7-15, 2015.

[23] F. Muscara, C. Catroppa, and V. Anderson, "The impact of injury severity on executive function 7-10 years following pediatric traumatic brain injury," Developmental Neuropsychology, vol. 33, no. 5, pp. 623-636, 2008.

[24] M. Beauchamp, C. Catroppa, C. Godfrey, S. Morse, J. V. Rosenfeld, and V. Anderson, "Selective changes in executive functioning ten years after severe childhood traumatic brain injury," Developmental Neuropsychology, vol. 36, no. 5, pp. 578595, 2011.

[25] E. Kim, E. C. Lauterbach, A. Reeve et al., "Neuropsychiatric complications of traumatic brain injury: a critical review of the literature (a report by the ANPA Committee on Research)," Journal of Neuropsychiatry and Clinical Neurosciences, vol. 19, no. 2, pp. 106-127, 2007.

[26] D. Velikonja, E. Warriner, and C. Brum, "Profiles of emotional and behavioral sequelae following acquired brain injury: cluster analysis of the Personality Assessment Inventory," Journal of Clinical and Experimental Neuropsychology, vol. 32, no. 6, pp. 610-621, 2010.

[27] R. Whelan-Goodinson, J. Ponsford, and M. Schönberger, "Validity of the Hospital Anxiety and Depression Scale to assess depression and anxiety following traumatic brain injury as compared with the Structured Clinical Interview for DSM-IV," Journal of Affective Disorders, vol. 114, no. 1-3, pp. 94-102, 2009.

[28] S. Sigurdardottir, N. Andelic, C. Røe, and A.-K. Schanke, "Depressive symptoms and psychological distress during the 
first five years after traumatic brain injury: relationship with psychosocial stressors, fatigue and pain," Journal of Rehabilitation Medicine, vol. 45, no. 8, pp. 808-814, 2013.

[29] M. Lovstad, I. Funderud, T. Endestad et al., "Executive functions after orbital or lateral prefrontal lesions: neuropsychological profiles and self-reported executive functions in everyday living," Brain Injury, vol. 26, no. 13-14, pp. 1586-1598, 2012.

[30] A. García-Molina, J. M. Tormos, M. Bernabeu, C. Junqué, and T. Roig-Rovira, "Do traditional executive measures tell us anything about daily-life functioning after traumatic brain injury in Spanish-speaking individuals?" Brain Injury, vol. 26, no. 6, pp. 864-874, 2012.

[31] G. P. Prigatano, "Disturbances of self-awareness and rehabilitation of patients with traumatic brain injury: a 20-year perspective," Journal of Head Trauma Rehabilitation, vol. 20, no. 1, pp. 19-29, 2005.

[32] A. Di Battista, C. Godfrey, C. Soo, C. Catroppa, and V. Anderson, "Does what we measure matter? Quality-of-life defined by adolescents with brain injury," Brain Injury, vol. 29, no. 5, pp. 573-582, 2015.

[33] J. M. Fletcher, H. S. Levin, D. Lachar et al., "Behavioral outcomes after pediatric closed head injury: relationships with age, severity, and lesion size," Journal of Child Neurology, vol. 11, no. 4, pp. 283-290, 1996.

[34] L. Green, C. Godfrey, C. Soo, V. Anderson, and C. Catroppa, "Agreement between parent-adolescent ratings on psychosocial outcome and quality-of-life following childhood traumatic brain injury," Developmental Neurorehabilitation, vol. 15, no. 2, pp. 105-113, 2012.

[35] A. Di Battista, C. Soo, C. Catroppa, and V. Anderson, "Quality of life in children and adolescents post-TBI: a systematic review and meta-analysis," Journal of Neurotrauma, vol. 29, no. 9, pp. 1717-1727, 2012.

[36] B. A. Bush, T. A. Novack, J. F. Malec, A. Y. Stringer, S. R. Millis, and A. Madan, "Validation of a model for evaluating outcome after traumatic brain injury," Archives of Physical Medicine and Rehabilitation, vol. 84, no. 12, pp. 1803-1807, 2003.

[37] J. F. Malec, A. W. Brown, and A. M. Moessner, "Personality factors and injury severity in the prediction of early and late traumatic brain injury outcomes," Rehabilitation Psychology, vol. 49, no. 1, pp. 55-61, 2004.

[38] J. Donders, Y. I. Oh, and J. Gable, "Self- and informant ratings of executive functioning after mild traumatic brain injury," Journal of Head Trauma Rehabilitation, 2015.

[39] L. Chamelian and A. Feinstein, "The effect of major depression on subjective and objective cognitive deficits in mild to moderate traumatic brain injury," Journal of Neuropsychiatry and Clinical Neurosciences, vol. 18, no. 1, pp. 33-38, 2006.

[40] G. Misic-Pavkov, Z. Novovic, K. Bozic et al., "Forensic aspect of late subjective complaints after traumatic brain injury," European Review for Medical and Pharmacological Sciences, vol. 16, no. 13, pp. 1806-1813, 2012.

[41] A. Olsen, J. F. Brunner, K. A. I. Evensen, B. Garzon, N. I. Landrø, and A. K. Håberg, "The functional topography and temporal dynamics of overlapping and distinct brain activations for adaptive task control and stable task-set maintenance during performance of an fMRI-adapted clinical continuous performance test," Journal of Cognitive Neuroscience, vol. 25, no. 6, pp. 903-919, 2013.
[42] N. U. F. Dosenbach, D. A. Fair, F. M. Miezin et al., "Distinct brain networks for adaptive and stable task control in humans," Proceedings of the National Academy of Sciences of the United States of America, vol. 104, no. 26, pp. 11073-11078, 2007.

[43] D. M. Little, M. F. Kraus, J. Joseph et al., “Thalamic integrity underlies executive dysfunction in traumatic brain injury," Neurology, vol. 74, no. 7, pp. 558-564, 2010.

[44] K. M. Kinnunen, R. Greenwood, J. H. Powell et al., "White matter damage and cognitive impairment after traumatic brain injury," Brain, vol. 134, no. 2, pp. 449-463, 2011.

[45] R. Scheid, K. Walther, T. Guthke, C. Preul, and D. Y. von Cramon, "Cognitive sequelae of diffuse axonal injury," Archives of Neurology, vol. 63, no. 3, pp. 418-424, 2006.

[46] K. G. Moen, T. Skandsen, M. Folvik et al., "A longitudinal MRI study of traumatic axonal injury in patients with moderate and severe traumatic brain injury," Journal of Neurology, Neurosurgery and Psychiatry, vol. 83, no. 12, pp. 1193-1200, 2012.

[47] A. K. Håberg, A. Olsen, K. G. Moen et al., "White matter microstructure in chronic moderate-to-severe traumatic brain injury: impact of acute-phase injury-related variables and associations with outcome measures," Journal of Neuroscience Research, vol. 93, no. 7, pp. 1109-1126, 2015.

[48] A. Olsen, J. F. Brunner, K. A. Indredavik Evensen et al., "Altered cognitive control activations after moderate-to-severe traumatic brain injury and their relationship to injury severity and everyday-life function," Cerebral Cortex, vol. 25, no. 8, pp. 2170-2180, 2015.

[49] S. S. Dikmen, C. H. Bombardier, J. E. Machamer, J. R. Fann, and N. R. Temkin, "Natural history of depression in traumatic brain injury," Archives of Physical Medicine and Rehabilitation, vol. 85, no. 9, pp. 1457-1464, 2004.

[50] T. Holsinger, D. C. Steffens, C. Phillips et al., "Head injury in early adulthood and the lifetime risk of depression," Archives of General Psychiatry, vol. 59, no. 1, pp. 17-22, 2002.

[51] S. Vaishnavi, V. Rao, and J. R. Fann, "Neuropsychiatric problems after traumatic brain injury: unraveling the silent epidemic," Psychosomatics, vol. 50, no. 3, pp. 198-205, 2009.

[52] R. Jorge and R. G. Robinson, "Mood disorders following traumatic brain injury," International Review of Psychiatry, vol. 15, no. 4, pp. 317-327, 2003.

[53] R. E. Jorge, L. Acion, S. E. Starkstein, and V. Magnotta, "Hippocampal volume and mood disorders after traumatic brain injury," Biological Psychiatry, vol. 62, no. 4, pp. 332-338, 2007.

[54] H. S. Levin, S. A. Brown, J. X. Song et al., "Depression and posttraumatic stress disorder at three months after mild to moderate traumatic brain injury," Journal of Clinical and Experimental Neuropsychology, vol. 23, no. 6, pp. 754-759, 2001.

[55] C. W. Jamora, A. Young, and R. M. Ruff, "Comparison of subjective cognitive complaints with neuropsychological tests in individuals with mild vs more severe traumatic brain injuries," Brain Injury, vol. 26, no. 1, pp. 36-47, 2012.

[56] S. C. Stein and C. Spettell, "The head injury severity scale (HISS): a practical classification of closed-head injury," Brain Injury, vol. 9, no. 5, pp. 437-444, 1995.

[57] R. M. Roth, C. E. Lance, P. K. Isquith, A. S. Fischer, and P. R. Giancola, "Confirmatory factor analysis of the behavior rating inventory of executive function-adult version in healthy 
adults and application to attention-deficit/hyperactivity disorder," Archives of Clinical Neuropsychology, vol. 28, no. 5, pp. 425434, 2013.

[58] J. K. Waid-Ebbs, P.-S. Wen, S. C. Heaton, N. J. Donovan, and C. Velozo, "The item level psychometrics of the behaviour rating inventory of executive function-adult (BRIEF-A) in a TBI sample," Brain Injury, vol. 26, no. 13-14, pp. 1646-1657, 2012.

[59] T. M. R. Achenbach and L. A. Rescorla, Manual for the ASEBA Adult Forms \& Profiles, Research Center for Children, Youth and Families, University of Vermont, Burlington, Vt, USA, 2003.

[60] G. Teasdale and B. Jennett, "Assessment of coma and impaired consciousness. A practical scale," The Lancet, vol. 304, no. 7872, pp. 81-84, 1974.

[61] T. Skandsen, K. A. Kvistad, O. Solheim, I. H. Strand, M. Folvik, and A. Vik, "Prevalence and impact of diffuse axonal injury in patients with moderate and severe head injury: a cohort study of early magnetic resonance imaging findings and 1-year outcome," Journal of Neurosurgery, vol. 113, no. 3, pp. 556-563, 2010.

[62] T. Skandsen, T. G. Finnanger, S. Andersson, S. Lydersen, J. F. Brunner, and A. Vik, "Cognitive impairment 3 months after moderate and severe traumatic brain injury: a prospective follow-up study," Archives of Physical Medicine and Rehabilitation, vol. 91, no. 12, pp. 1904-1913, 2010.

[63] J. T. L. Wilson, L. E. L. Pettigrew, and G. M. Teasdale, "Structured interviews for the glasgow outcome scale and the extended glasgow outcome scale: guidelines for their use," Journal of Neurotrauma, vol. 15, no. 8, pp. 573-580, 1998.

[64] A. Smith, Symbol Digit Modality Test, Ninth Printing 2002, (SDMT) Manual, Western Psyhological Services, Los Angeles, Calif, USA, 1982.

[65] D. C. Delis, E. Kaplan, and J. Kramer, Delis Kaplan Executive Function System, The Psychological Corporation, San Antonio, Tex, USA, 2001.

[66] C. K. Conners and M. Staff, Conners' Continuous Performance Test II (CPT II) Computer Program for Windows, Technical Guide and Software Manual, Multi-Health Systems, Toronto, Canada, 2000.

[67] D. C. Delis, J. H. Kramer, E. Kaplan, and B. A. Ober, California Verbal Learning Test, Second Edition (CVLT-II). Adult Version, Manual, The Psychological Corporation, San Antonio, Tex, USA, 2000.

[68] J. E. Meyers and K. R. Meyers, Rey Complex Figure Test and Recognition Trial: Professional Manual, Psychological Assessment Resource, Odessa, Ukraine, 1995.

[69] D. E. Trahan and G. J. Larrabee, Continous Visual Memory Test, Psychological Assessment Resources, Odessa, Fla, USA, 1988.

[70] R. K. Heaton, Wisconsin Card Sorting Test, Computer Version-2 Research Edition, Psychological Assessment Resources, Odessa, Fla, USA, 1993.

[71] M. D. Lezak, D. B. Howieson, and D. W. Loring, Neuropsychological Assessment, Oxford University Press, Oxford, UK, 4th edition, 2004.

[72] D. Wechsler, Wechsler Abbreviated Scale of Intelligence Scale, The Psychological Corporation, San Antonio, Tex, USA, 1999.

[73] A. T. Beck, A. J. Rush, B. F. Shaw, and G. Emery, Cognitive Therapy of Depression, Guilford Press, New York, NY, USA, 1979.
[74] R. J. Grissom and J. J. Kim, Effect Sizes for Research. A Broad Practical Approach, Lawrence Erlbaum Associates, New York, NY, USA, 2005.

[75] J. Cohen, Statistical Power Analysis for the Behavioral Sciences, Erlbaum, Hillsdale, NJ, USA, 2nd edition, 1988.

[76] S. Lydersen, M. W. Fagerland, and P. Laake, "Recommended tests for association in $2 \times 2$ tables," Statistics in Medicine, vol. 28, no. 7, pp. 1159-1175, 2009.

[77] M. W. Fagerland, S. Lydersen, and P. Laake, "Recommended confidence intervals for two independent binomial proportions," Statistical Methods in Medical Research, vol. 24, no. 2, pp. 224-254, 2015.

[78] D. M. D. Altman, T. Bryant, and S. Gardner, Statistics with Confidence, John Wiley \& Sons, New York, NY, USA, 2nd edition, 2000.

[79] S. Rosema, F. Muscara, V. Anderson, C. Godfrey, S. Hearps, and C. Catroppa, "The trajectory of long-term psychosocial development 16 years following childhood traumatic brain injury," Journal of Neurotrauma, vol. 32, no. 13, pp. 976-983, 2015.

[80] L. A. Rabin, R. M. Roth, P. K. Isquith et al., "Self- and informant reports of executive function on the BRIEF-A in MCI and older adults with cognitive complaints," Archives of Clinical Neuropsychology, vol. 21, no. 7, pp. 721-732, 2006.

[81] S. Rotenberg-Shpigelman, R. Rapaport, A. Stern, and A. Hartman-Maeir, "Content validity and internal consistency reliability of the Behavior Rating Inventory of Executive FunctionAdult Version (BRIEF-A) in Israeli adults with attentiondeficit/hyperactivity disorder," Israeli Journal of Occupational Therapy, vol. 17, no. 2, pp. 77-96, 2008.

[82] K. A. Ragsdale, S. M. Neer, D. C. Beidel, B. C. Frueh, and J. W. Stout, "Posttraumatic stress disorder in OEF/OIF veterans with and without traumatic brain injury," Journal of Anxiety Disorders, vol. 27, no. 4, pp. 420-426, 2013.

[83] J. Toglia, M. V. Johnston, Y. Goverover, and B. Dain, "A multicontext approach to promoting transfer of strategy use and self regulation after brain injury: an exploratory study," Brain Injury, vol. 24, no. 4, pp. 664-677, 2010.

[84] M. H. Beauchamp and V. Anderson, "SOCIAL: an integrative framework for the development of social skills," Psychological Bulletin, vol. 136, no. 1, pp. 39-64, 2010.

[85] D. Hoofien, A. Gilboa, E. Vakil, and P. J. Donovick, "Traumatic brain injury (TBI) 10-20 years later: a comprehensive outcome study of psychiatric symptomatology, cognitive abilities and psychosocial functioning," Brain Injury, vol. 15, no. 3, pp. 189209, 2001.

[86] G. P. Prigatano, "Impaired self-awareness after moderately severe to severe traumatic brain injury," in Re-Engineering of the Damaged Brain and Spinal Cord, vol. 93 of Acta Neurochirurgica Supplementum, pp. 39-42, Springer, Vienna, Austria, 2005.

[87] L. R. Gentry, J. C. Godersky, and B. Thompson, "MR imaging of head trauma: review of the distribution and radiopathologic features of traumatic lesions," American Journal of Roentgenology, vol. 150, no. 3, pp. 663-672, 1988.

[88] J. Ponsford, K. Draper, and M. Schönberger, "Functional outcome 10 years after traumatic brain injury: its relationship with demographic, injury severity, and cognitive and emotional status," Journal of the International Neuropsychological Society, vol. 14, no. 2, pp. 233-242, 2008. 
[89] R. T. Seel, S. MacCiocchi, and J. S. Kreutzer, "Clinical considerations for the diagnosis of major depression after moderate to severe TBI," The Journal of Head Trauma Rehabilitation, vol. 25, no. 2, pp. 99-112, 2010.

[90] M. V. Johnston, "Neurotransmitters and vulnerability of the developing brain," Brain and Development, vol. 17, no. 5, pp. 301306, 1995.

[91] D. T. Stuss, "Science mirroring reality: an improbable journey into the functions of the frontal lobes," Archives of Clinical Neuropsychology, vol. 28, no. 1, pp. 1-8, 2013.

[92] K. Cicerone, H. Levin, J. Malec, D. Stuss, J. Whyte, and E. Edwards, "Cognitive rehabilitation interventions for executive function: moving from bench to bedside in patients with traumatic brain injury," Journal of Cognitive Neuroscience, vol. 18, no. 7, pp. 1212-1222, 2006.

[93] I. Funderud, M. Lindgren, M. Løvstad et al., "Differential Go/NoGo activity in both contingent negative variation and spectral power," PLoS ONE, vol. 7, no. 10, Article ID e48504, 2012. 


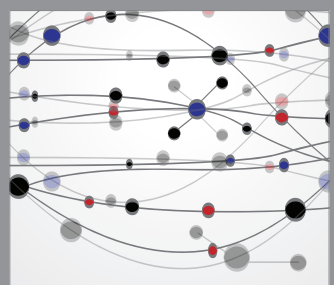

The Scientific World Journal
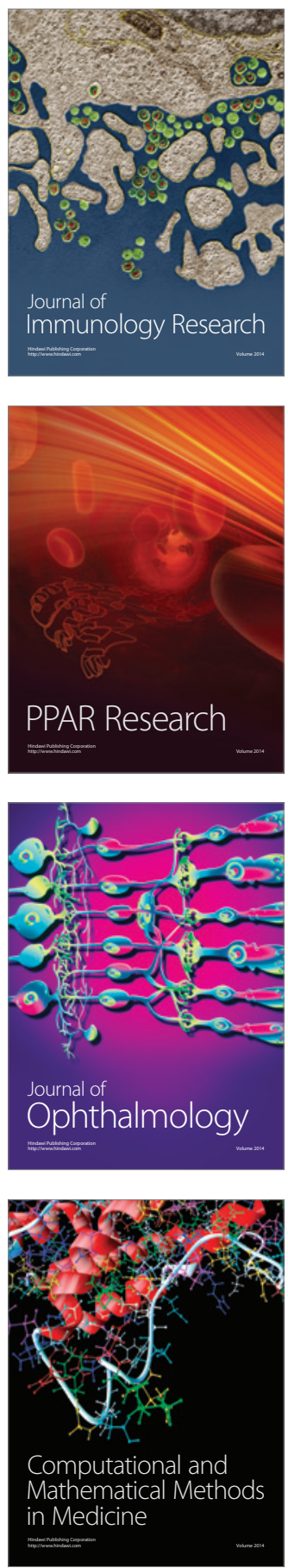

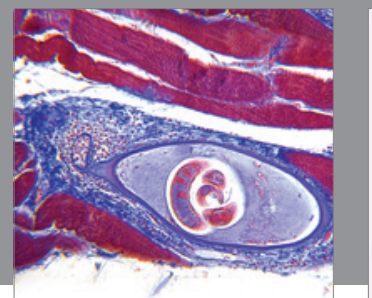

Gastroenterology

Research and Practice
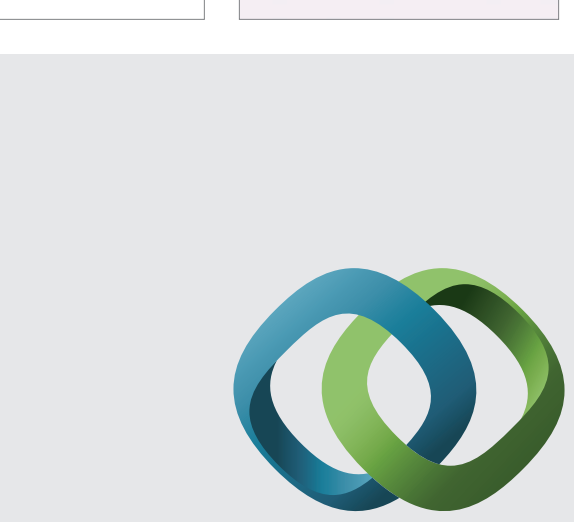

\section{Hindawi}

Submit your manuscripts at

http://www.hindawi.com
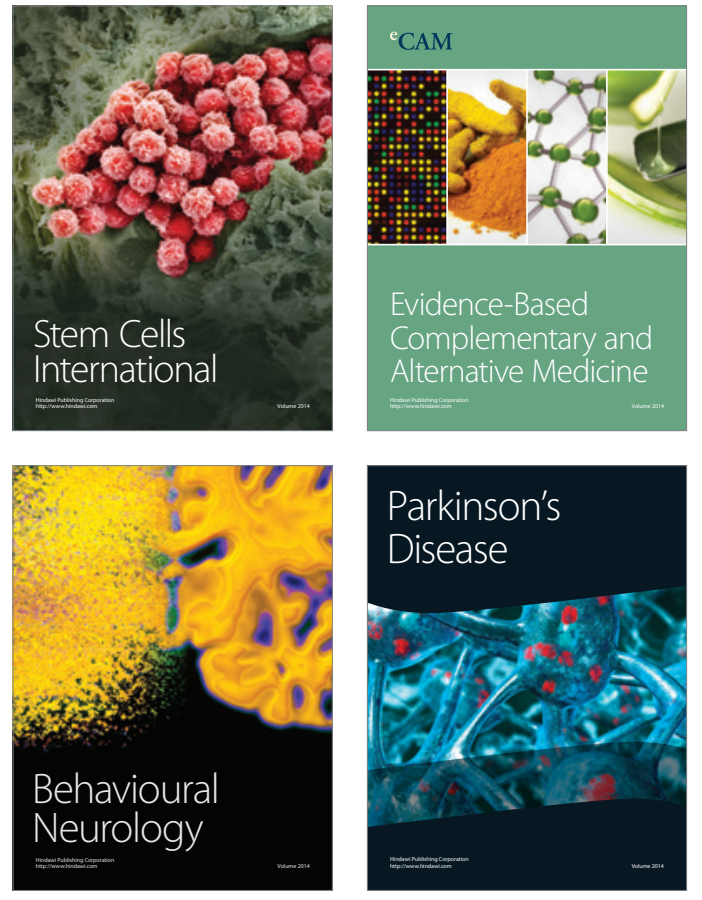
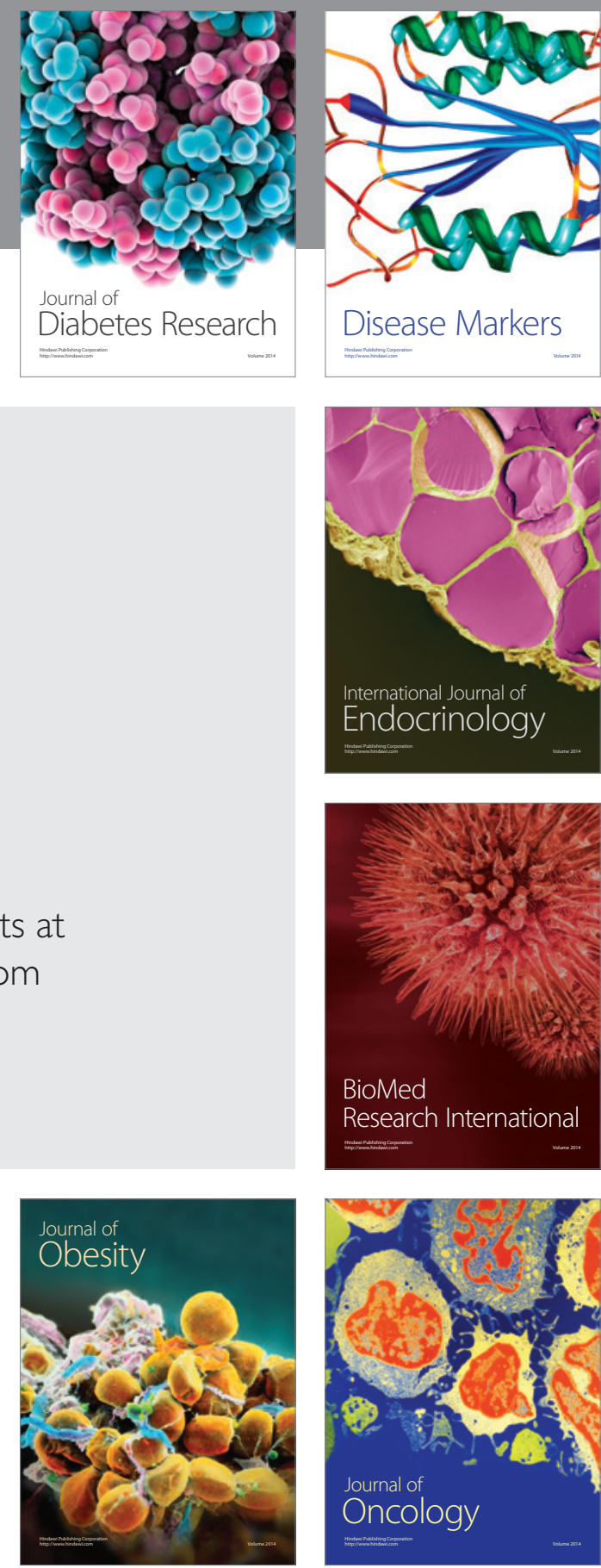

Disease Markers
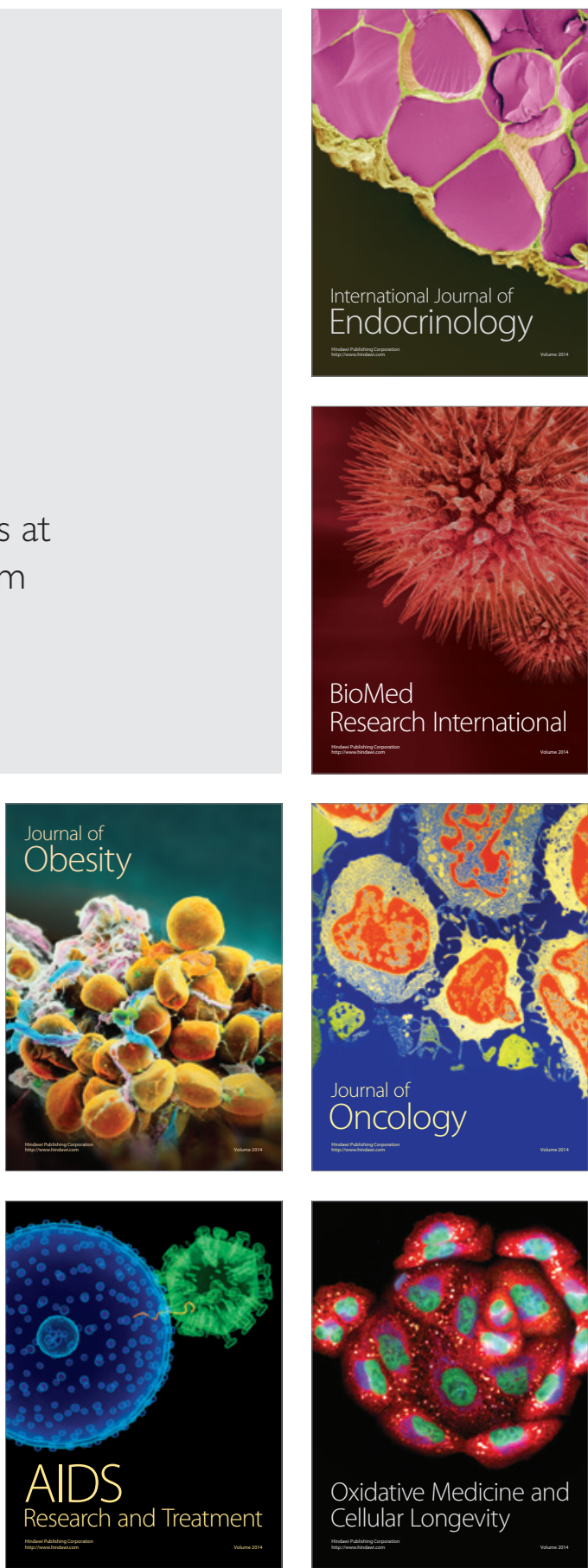